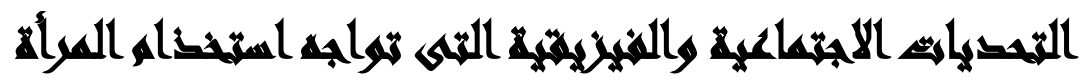

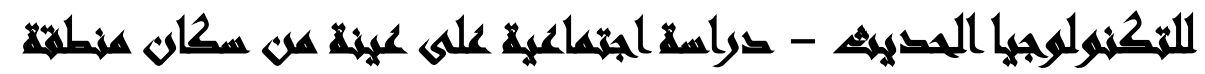 \\ الجيزلة}

\section{[Ir]}
مصطفى ابراهيم عوض(')- محمود عبد الحميد حسين(ץ) - السيد محمد الهربيطى(") نانسى حسين بيومى أبو صوان التيان

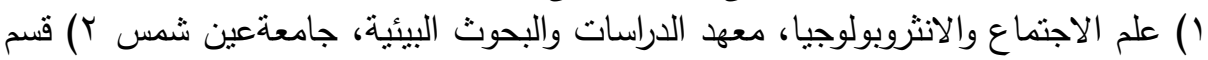

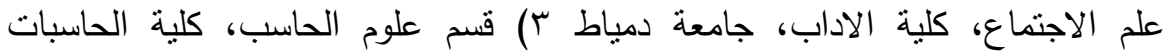
والمعلومات جامعة عين شمس الادس

\section{المسنطلئ}

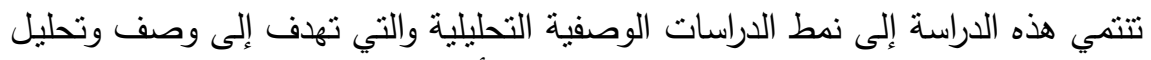

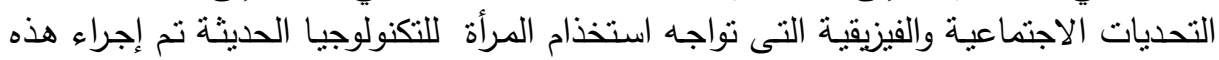

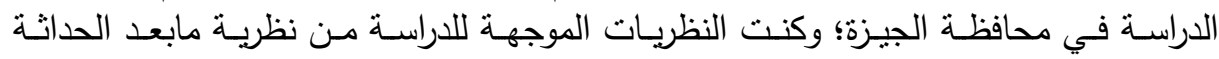

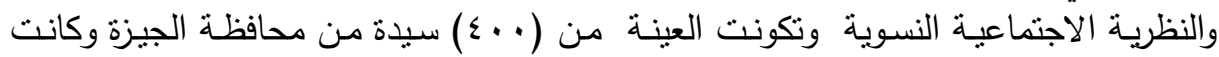

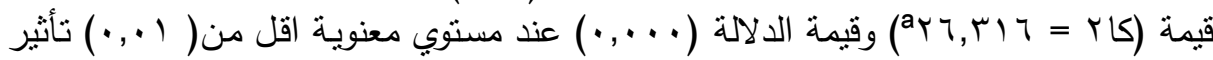

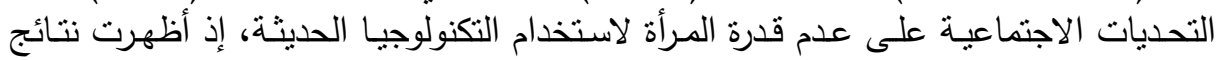

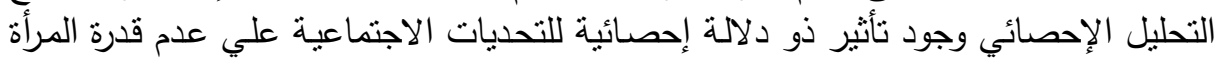

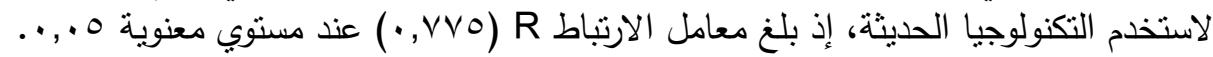

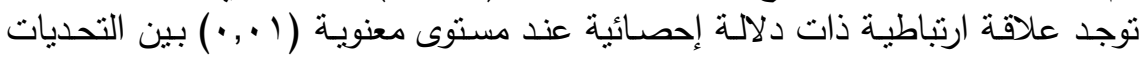

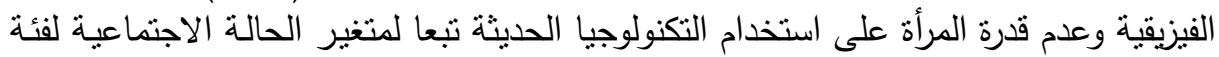

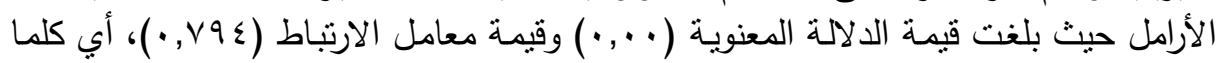

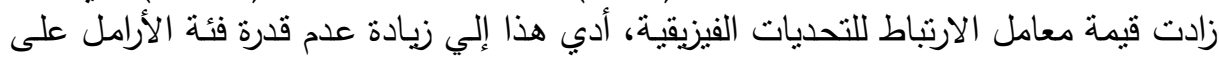
استخدام التكنولوجيا الحديثة.

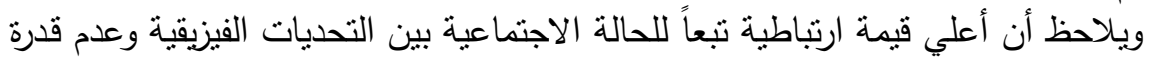

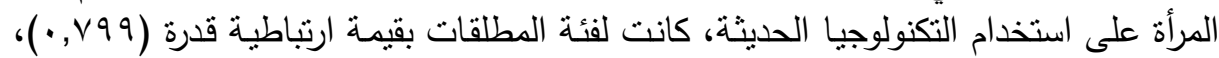

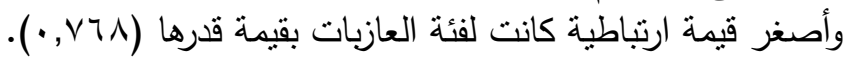

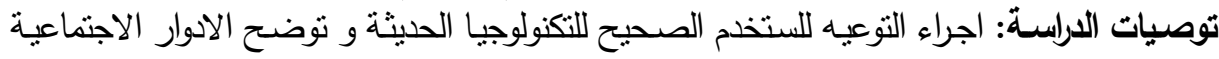
التى تقوم بها المراء في ظل انساع الفجواه بين التكنولوجيا الحديثة ومهام الامراء.

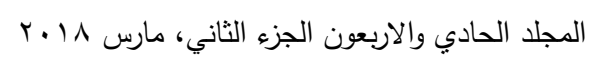




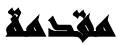

تمثل المرأة نصف المجتمع، وصدق وهي ايضا الأم والأخت والزوجة، ولكن ما لا يصدق هو أن المرأة العصرية في الأونه الاخيرة بدأت تحس بأنها لم تعد تتمتع بهذه الصفات والميزات بسبب المسؤولية الاجتماعية الملقاة على عاتقها، وصعوبة التعامل مع تلك المسؤولية هو شعور كثير من النساء العصريات فرضته مشاكل الحياة عليهن، فوقعن أمام خبارين: إما الاستسلام أو التعامل مع هذه المشاكل، بشكل عصري. ففي دراسة أطلقها معهد 》آيرتونه البرازيلي، المتخصص بالدراسيات الاجتماعية، كثف أن المرأة العصرية تشكو من أمور كانت تمنل حلمًا بالنسبة للمرأة القديمة التي حرمت من

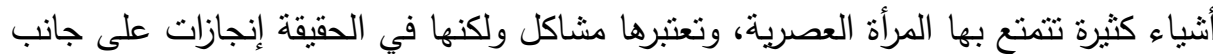

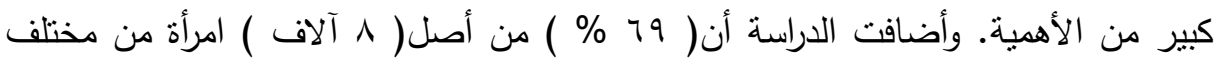
الجنسيات، نم سؤالهن عن المشاكل العصرية للمرأة، أكدن أن وضع المرأة العصرية أصبح

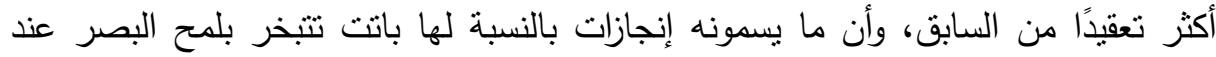

مقارنتها بالإنجازات التي يتمتع بها الرجل العصري. (Hanmer \& statham, 2009).

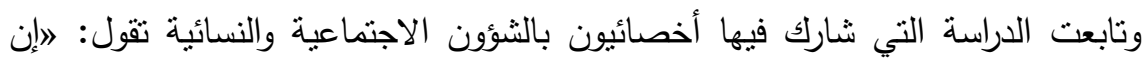

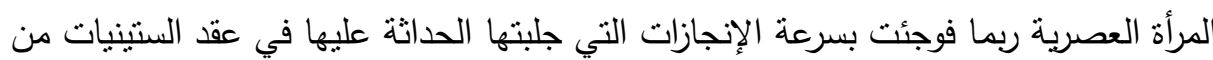
القرن الماضي في أوروبا على وجه الخصوص، فخلال نحو خمسين عامًا هناك انقرضت نظريات وفرضيات عن المرأة، ودورها في المجتمع كانقراض الديناصورات، والفترة تعتبر قصيرة إذا ما قورنت بالمزايا التي يتمتع بها الرجال منذ آلاف السنين.( ميسون ضيف فيف الله

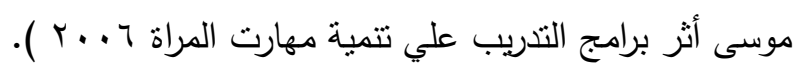

قد تكون حصلت المرأة من حقوق في أوروبا والولايات المتحدة وبعض بلداندان بلدان أميركا

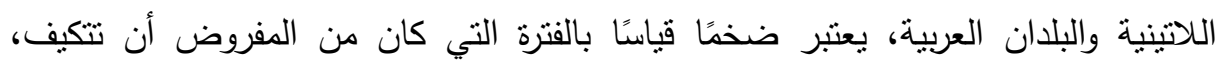

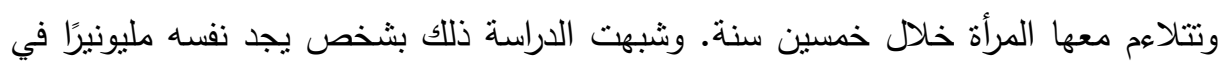
لحظة لربحه جائزة اليانصيب، فذلك الثخص إذا كان معدومًا طوال حياته فسيجد صعوبة

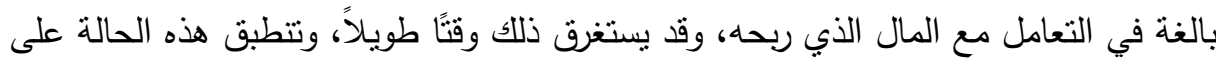


النساء العصريات، اللواتي وجدن أنفسهن أمام تغييرات هائلة في خمسين عامًا من أصل آلاف

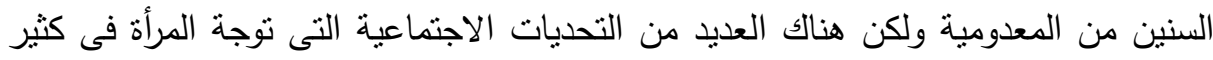
من المجلات والعمال اما بضغوط عمل وتأثير سلبي لتتمية والعمل الثاق في بلدان العالم

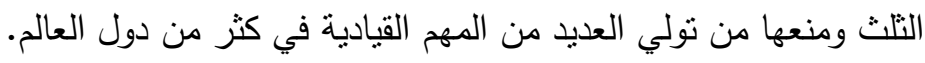

\section{مش2}

يشكل الحديث عن التحديات التي تواجه المرأة نقطة تقاطع ما بين ثقافة العزل والتهميش والتمبيز وبين ثقافة النوع والمشاركة، فالثقافة السائدة تحول المرأة إلى كائن محبط لأل مهمش فاقد لأبسط حقوق الانسانية باسم الثرف تارة وباسم الحفاظ على قيم الاسرة تارة أخرى غير أن عملية تمكين المرأة تقتح لها نوافذ وعي جديد بذاتها، وتهيئ المجتمع لخلق تصورات الهات

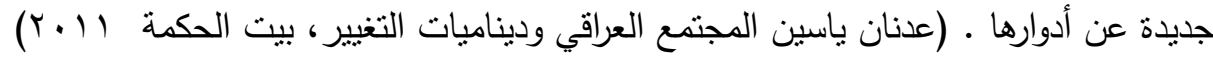

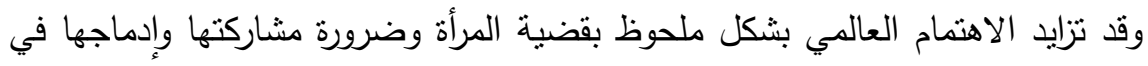

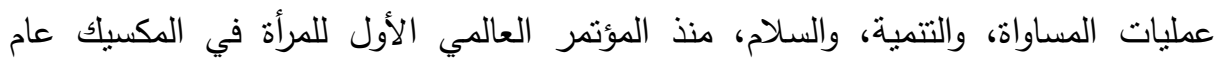

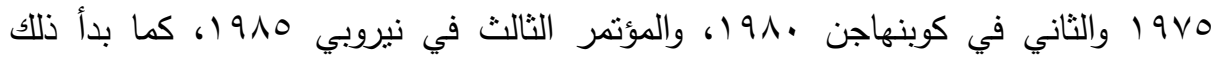

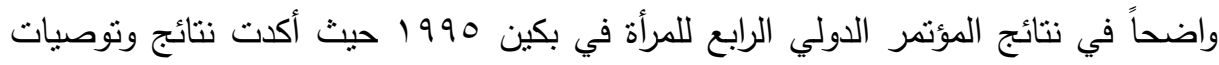
هذه اللقاءات على بعض المصطلحات أو المناهج التي تحمل مفاهيم تتموية هامة مثل منهج التمكين للمرأة وهناك العديد من الدراسات والتي تهدف إلى تعزيز صورة المرأة عن نفسها، وتقتها بقدراتها الذاتية، وقيمتها في المنزل والمجتمع. ( ميسون ضيف الله موسى أثر برامج

$$
\text { التدريب علي تتمية مهارت المراة ؟ . . r ). }
$$

وقد قام الباحثون بعل دراسة الاستطلاعية على عينة مكونة من (•r) سيدة تهنم

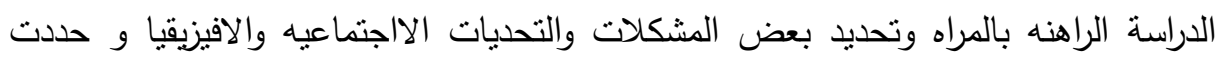
الدراسة عدد من المشاكل الرئيسة التي تواجهها المرأة العصرية بحسب مفهومها مع أنها تعتبر

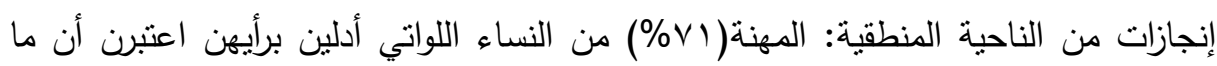

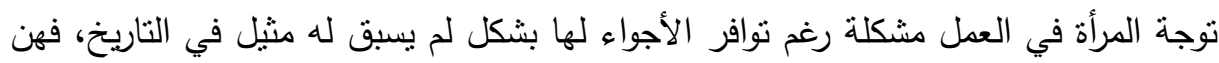

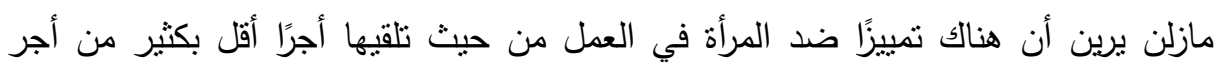

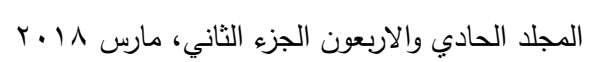


الرجل حتى في الدول المتقدمة خاصه في القطاع الخاص. وعلقت الدراسة: لاربما يكون في هذا جانب من الحقيقة، ولكن ماذا عن الفترة التي سبقت الثورة التحررية للمرأة في ستنيات التيات العقد الماضي«؟

تهتم الدراسة بتحديد المشكلات الاجتماعية الناتجة من نركم خبرات وثقافة المجتمع

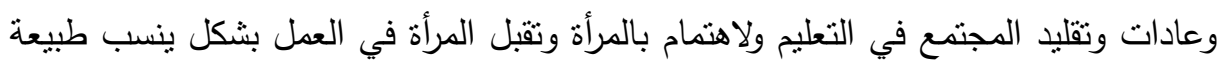

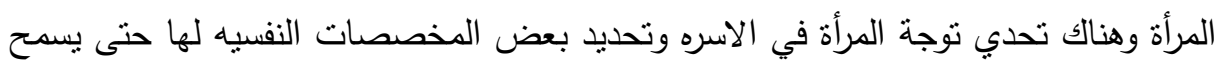

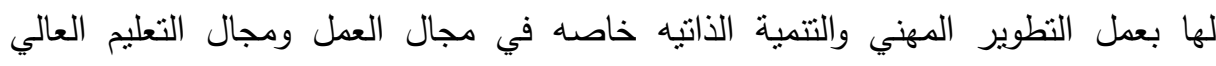
والدراسات العالية وتعزيز استخدم وتعلم التكنولوجيا الحدية والتعمل معها بشكل امن وسليم وهنالك تحدى من المرأة نفسها وما تهدر من وقت في استخدم بعض التكنولوجيا بشكل سلبي وتجعل منها منفز لها في التعمل الافتراضي بشكل سلبي وهناك عدد من من النساء يستخدم التكلنولوجيا بشكل إيجابي ولكن يبقى الوقت واهدار الوقت وحدوث تقير في الادوار والمهر التي ينبغي عليها ان تقوم بها.

\section{هروض الصراهية}

ا-يوجد تأثنير ذو دلالــة إحصـائية للتحديات الاجتماعيـة على عدم قدرة المـرأة لاسـتخدام التكنولوجيا الحديثة.

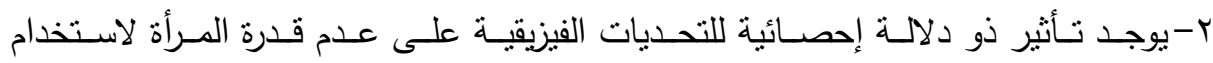
التكنولوجيا الحديثة. r-يوجد تأثير ذو دلالة إحصائية للتحديات الاجتماعية والفيزيقية معا على عدم قدرة المرأة لاستخدام التكنولوجيا الحديثة. ع-توجد فروق ذات دالـة إحصـائية في التحديات الاجتماعيـة بين سيدات الريف وسيدات الحضر • ه-توجد فروق ذات دالة إحصائية في التحديات الفيزيقية بين سيدات الريف وسيدات الحضر . 
צ-توجد فروق ذات دالة إحصائية في التحديات الاجتماعية والفيزيقية معا بين سيدات الريف

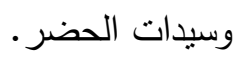

V-توجـد فـروق ذات دالـة إحصـائية في مسـتوي اسـتخدام التكنولوجيـا تبعـا لمتغيـر الحالـة الاجتماعية.

\section{أهساهيم الصواسما}

1-تحديد التحديات الاجتماعية على تواجه قدرة المرأة عند استخدام التكنولوجيا الحديثة. r-تحيد التحديات الفيزيقية التي نواجه على قدرة المرأة عند استخدام التكنولوجيا الحديثة. r-تحديد الاثار السلبية الناتجة عن إستخدام المراة للتكنولوجيا الحديثة. ع-تصور مقترح حول الاسلوب الأمثل لمواجة المرأه لتلك التحديات.

\section{أهمية التراسة}

تتحدد أهمية الدراسة في جانبين هما:

أولاً: الأهمية النظرية وتتضح فيما يلي: أهمية تتاولت موضوع التحديات الاجتماعية والفيزيقية معا على عدم قدرة المرأة لاستخدام التكنولوجيا الحديثة وتحديد المتغيرات التى تزيد من تفاقم الفجوه بين حصول المراة على حقها من التتمية والمشاركة بها.

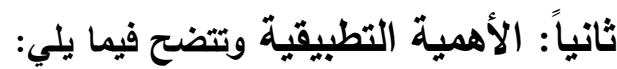
1. يستقفي العاملون في مجال التأهيل والتدريب من هذه الدراسة في الوقوف على احتياجات هذه م الفئة وتقديم الخدمات المناسبة له. r. و تستقبد كذلك مؤسسات الدولة في تطوير البيئية المحيطة والحفاظ على الامن

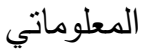
r. ويستقبد منها العاملون في مجال التعليم كالمدرسين و المربين .....إلخ. ع. ويستقد منها الأبوين في التعامل مع أولدهم في التتشئة والتربية السوية وكيفه التعامل المتغيرات الحديثة والاستخدام الصحيح للتكنولوجيا الحديثة. 


\section{المهاهمير}

استعانت الباحثه بعدد من المصطلحات هي:

ا. التحديات الاجتماعية هي: التحدي هو ذلك الوضع الذي يمثل وجوده أو عدم وجوده

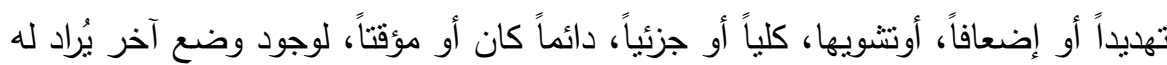

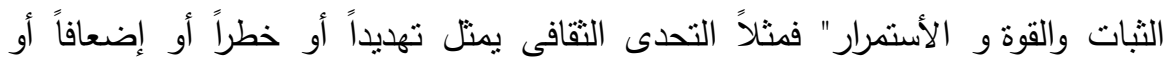

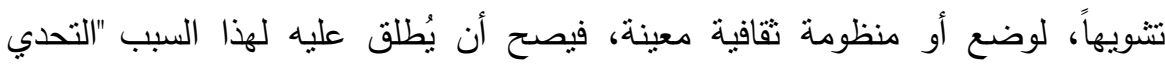
الثقافي.

وهناك تعريف آخر للتحديات مفاده أن " التحديات هى تطورات أو متغيرات أو مشكلات

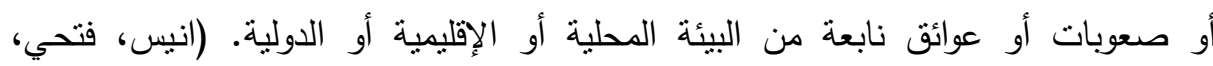

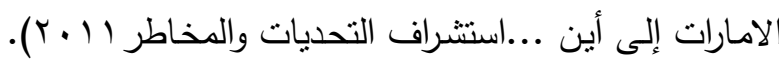
مفهوم النوع Gender: إن مفهوم المرأة ذاته فى إطار النظريات الاجتماعية والسياسية الغربية قد تبلور فى صورة ما بمكن أن نطلق عليه الخطاب النسوى أو الاتجاه النسوى

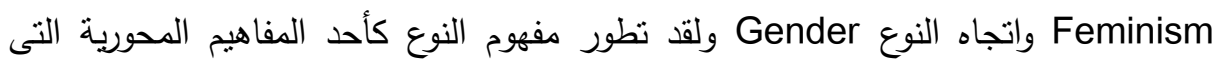

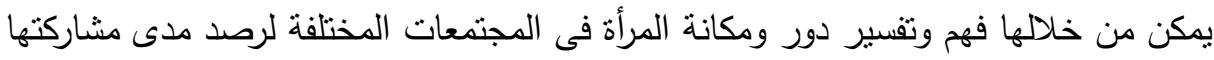
فى العملية الإنتاجية.

وقد ظهر مفهوم النوع فى النمانينات كنموذج نظرى مسيطر ، حيث يلقى هذا المنظور

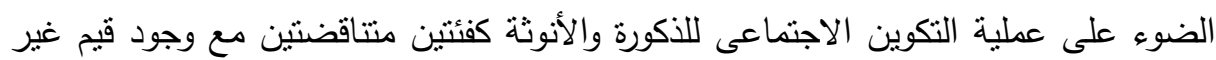
متساوية. ويركز نموذج النوع على الكيفية التى تضفى بها أنماط معينة من السلوك والأدوار

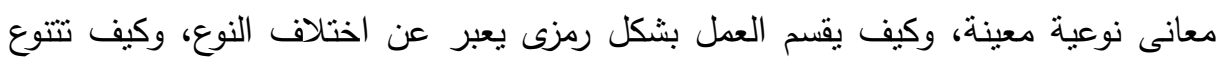

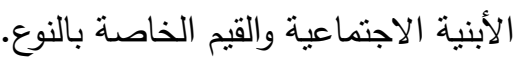
ولقد عرف "جون سكوت 1986 Joan Scott" النوع على أنه متغير بنائى فى بلى النى

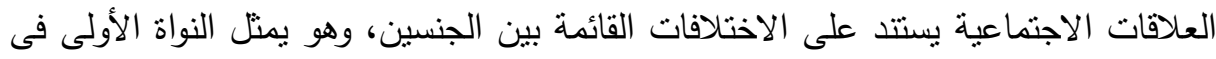
تشكيل علاقات قوة محدد. وفى مقابل مفهوم النوع الذى يركز على الاختلافات بين الجنسين 
والتى تتشكل اجنماعياً، نجد مفهوم الجنس الذى يشير إلى الفروق الطبيعية، أى المرتبطة بالجوانب البيولوجية

r. تعريف التكنولوجيا: يرجع أصل التكنولوجيا إلى الكلمة يونانية التي تتكون من مقطعين

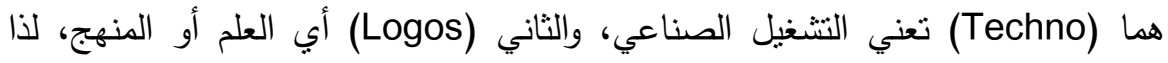
تكون بكلمة واحدة هي علم التشغيل الصناعي. ( غسان قاسم اللامي، إدارة التكنولوجيا، $(r+T$

ويمكن تعريفها من جهة التحليل الاقتصادي بأنها "مجموعة المعارف والمهارات والخبرات الجديدة التي يمكن تحويلها إلى طرف إنتاج أو استعمالها في إنتاج سلع وخدمات وتسويقها

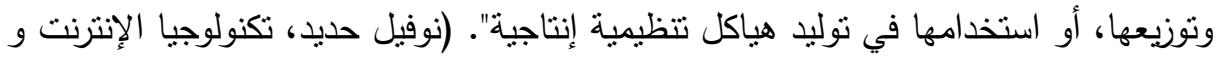

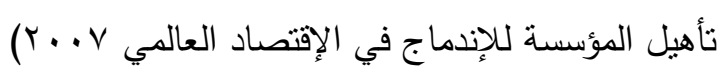
ويمكن تعريف التكنولوجيا على إنها :"نطبيق الإجراءات المستمدة من البحث العلمي

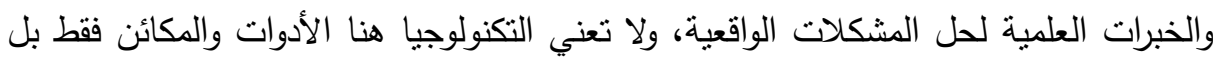
أنها الأسس النظرية والعلمية التي ترمي إلى تحسين الأداء البشري في الحركة التي تنتاولها". (عبد البارى، إبراهيم درة، تكنولوجيا الأداء البشري في المنظمات في البيئة العربية المعاصرة، أنواع التكنولوجيا: يتم تصنيف التكنولوجيا على أساس عدة أوجه منها مايلي : على أساس درجة التحكم نجد مايلي: التكنولوجيا الأساسية: وهي التكنولوجيا التي تمنلكها أغلب المؤسسات الصناعية والمسلم به وتتميز بدرجة التحكم كبير جدا. تكنولوجيا التمايز: وهي التي تملكها مؤسسة واحدة أو عدد محدود من المؤسسات الصناعية وهي التكنولوجيا التي تتميز بها عن بقية منافسيها. على أساس موضوعها هناك : تكنولوجيا التسبير: وهي التي تستخدم في نسير تدفقات موارد، ومن أمنتلها البرامج والتطبيقات التسيرية . 
تكنولوحيا التصميج: وهي التي تستخدم في نشاطات التصميم في المؤسسة كالتصميم بمساعدة

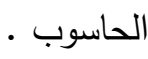

تكنولوجيا أسلوب الإنتاج: وهي تلاك المستخدمة في عماليات الصنع ، وعمليات التركيب والمراقبة.

تكنولوجيا المعلومات والاتصال: وهي التي تستخدم في معالجة المعلومات والمعطيات ونقلها ـ على أساس درجة النعقبد نجد:

تكنولوجيا ذات درجة عالبة: وهي التكنولوجيا شديدة التعقيد، والتي من الصعب على دلى

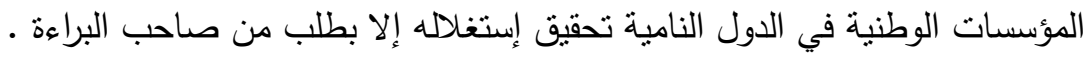

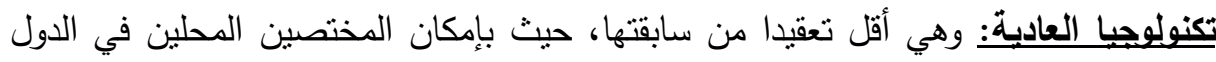
النامية إستبعابها غير أنها تتميز أيضا بضخامة تكاليف الإستثمار ـ (لمين علوطي، تكنولوجيا

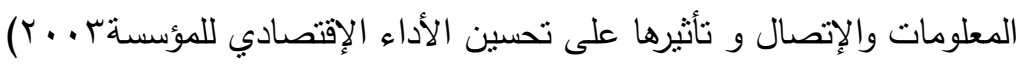

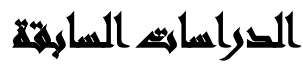

• دراسة الهيئة الوطنية لشؤون المرأة اللبنانية(11 ـ ب). بعنوان "الاستراتيجية

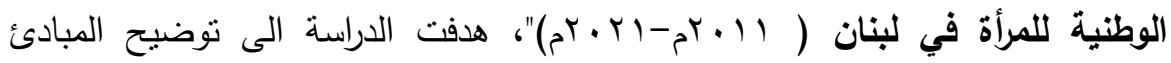
الاساسية للخطة الاستراتيجية الوطنية للمرأة في لبنان، اعتمدت الخطة الاستراتيجية على لهي

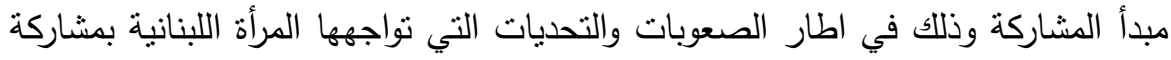
جميع الجهات الوطنية والرسمية والاهلية والاقليمية والدولية وذللك تعزيزاً للمرأة ودورها

$$
\text { الفعال في الاسرة المجتمع. }
$$

نتائج الدراسة: خرجت الدراسة بعدة اهداف استراتيجية لتمكين المرأة اللبنانية اجتماعياً

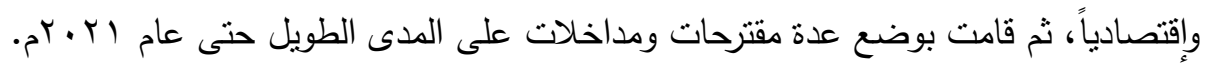
تم إيجاز هذه الاهداف في نقاط مهمة وهي: - - المساواة بين الرجل والمرأة في الحقوق والواجبات وإتخاذ القرارات. - ت توفير خدمات التعليم للمرأة والرعاية الصحية. 
- تعزيز مشاركة المرأة في الحياة الإقتصادية ومساهتها في حماية البيئة. - القضاء على الفقر بتوفير عمل للنساء وحمايتهن من النزاعات والحروب".

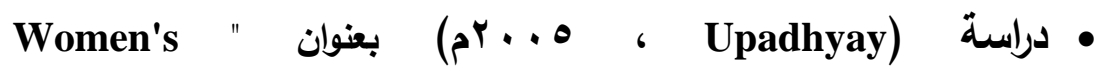
Empowerment in India في الهند على أن تعتمد بشكل كبير على عدة متغيرات رئيسية منها الموقع الجغرافي ( مدني ،خط ريفي) ،المستوى التعليمي ، الحالة الاجتماعية والعمر ،حيث يلاحظ ان هناك سياسات وطنية واقليمية وقطاعية لتمكين المرأة في التيكي

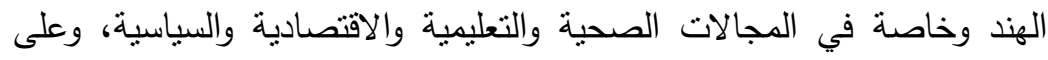
الرغم من ذلك لا تزال هناك هناك فجوة بينما تعلن عنه السياسات والمستوى وهيه

$$
\text { الفعلي لتمكين المرأة. }
$$

شخصت الدراسة عدة أسباب لهذه الفجوة منها: - ما يتعلق بالقوانين والسياسات

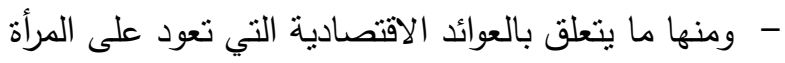
- - ومنها ما يخص انتهاك حقوق المرأة.

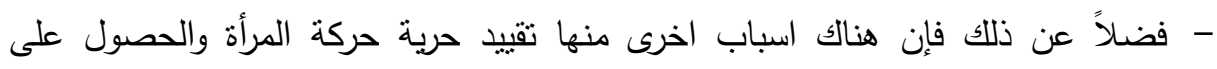
التعليم والخدمات الصحية وضعف المشاركة في اتخاذ القرار وقلة الخبرة.

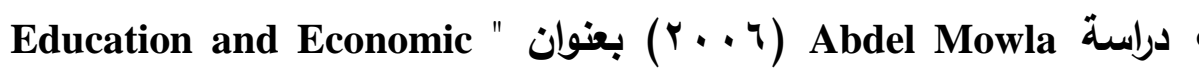
Empowerment of Women in Egypt سياسة نوضح العوامل المؤثرة على تمكين المرأة إقتصادياً وتعليمياً من خلال أربع مسنويات وهي المستوى الحرفي ، ومستوى العمل في الثركات، وعلى مسنوى الاقتصاد، وعلى مستوى الإقتصاد العالمي.

ومن أجل ذلك ركزت الدراسة على فحص العلاقة بين التمكين الاقتصادي والتعليمي للمرأة في مصر باستخدام بيانات سوق العمل المصري لعام ؟ +. بام. حيث نم التركيز على قدرة المرأة على العمل بأجور جيدة ونوعية عمل جيدة. 
خلصت الدراسة إلى إن التعليم يمكن المرأة من الحصول على القوة في سوق العمل،

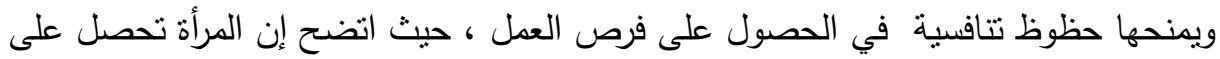
منفعة أكبر من الرجل عند حصولها على التعليم في مجال تحسين مخرجات سوف العمل.

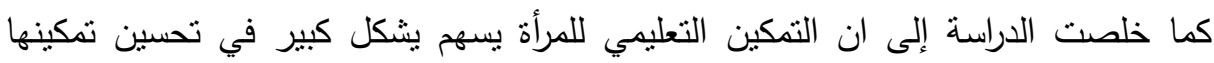

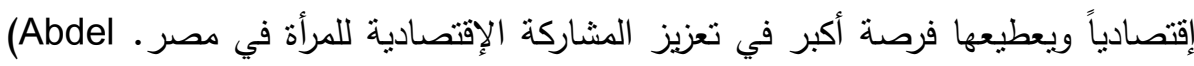
Mowla

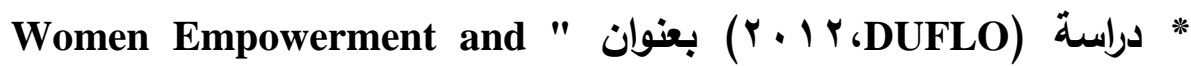
Economic Development والنطور الاقتصادي ،حيث افترض الباحث وجود علاقة قوية بين هذين المتغيرين حيث تم التركيز على دور المرأة في تحقيق التطور الاقتصادي وذلك ان معظم البحوث التي تمت بهذا الاطار ركزت على دور الرجل في تحقيق النطور الاقتصادي بشكل حقق عدم العدالة بين الرجل والمرأة في هذا المجال.

كما قام الباحث بمرجعة الادبيات المرتبطة بالموضوع والجدل حول العلاقة بين تمكين

$$
\text { المرأة والتطور الإقتصادي. }
$$

خلصت الدراسة الى ان تمكين المرأة سيؤدي إلى تحسين التطور الاقتصادي وتحقيق

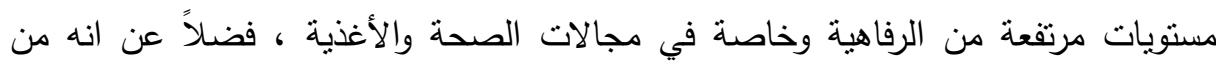
الضروري تحقيق موازنة بين دور المرأة ودور الرجل في تحقيق النطور الاقتصادي.

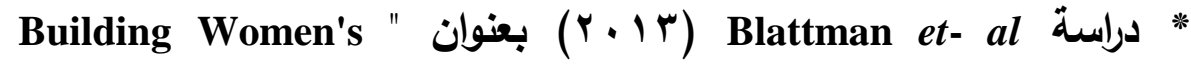
Economic and Social Empowerment Thruogh Enterprise "Uganda

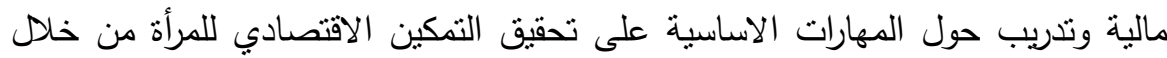
تصميم وتتفيذ برامج معده لهذا الغرض صممت من قبل منظمة ايطالية غير حكومية. 


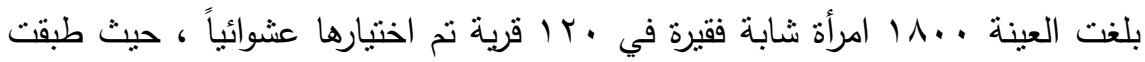
هذه البرامج عليهن لفترة 11 شهر وتم تقسيم النساء إلى مجموعات تحت إثراف مشرفين

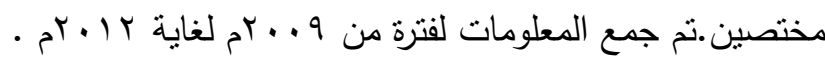

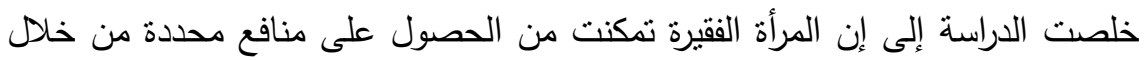

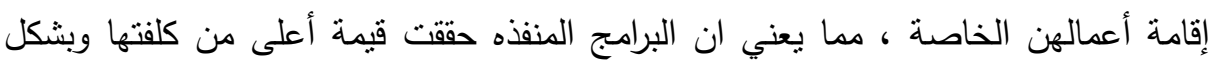

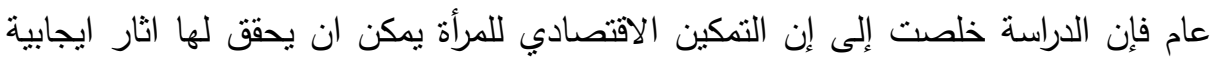
خاصةً في المجال الصحي.

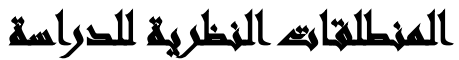

1- النظرية الاجتماعية النسويةة: تهنم النظرية الاجتماعية النسوية بالحياة الخاصة الملازمة للعلاقة بين المرأة والرجل، كما تهتم بالتغيرات التي تصاحب هذه العلاقة خاصة

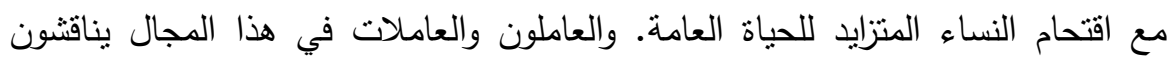
ويناقتن الاعتقاد القائم بطول وصعوبة الطريق أمام إحراز المساواة في العلاقة بين الرجل والمرأة، على الرغم من أن الرجال والنساء يشكلون ويشكلن نماذج هذه العلاقة وذلك بفضل

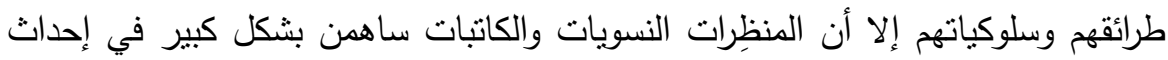
تغيير في المجتمعات تبعه تغييرا وتأثيرا على تلك العلاقة. ولعل الفضل يعود في ذلك إلى إنى

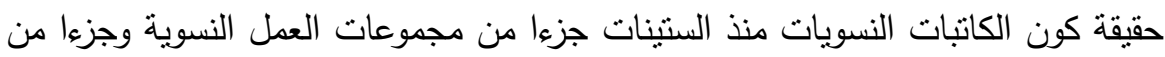
الحراك السياسي والاجتماعي في تلك الفترة. أما في الوقت الحالي فنتواصل الكاتبات النسويات تواجدهن في مختلف الأنشطة والميادين.

وإلى جيل مضى لم تكن النظرية النسوية جزء من علم الاجتماع - مع العلم - أن الفكر فئه

النسوي قد ساهم في صياغة - ليس فقط - النظرية النسوية وإنما النظرية الاجتماعية ككل.

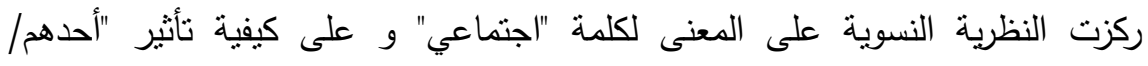

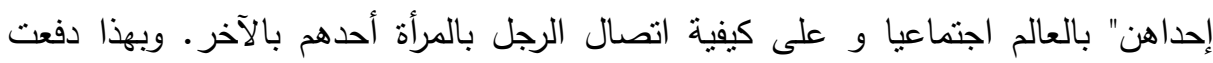

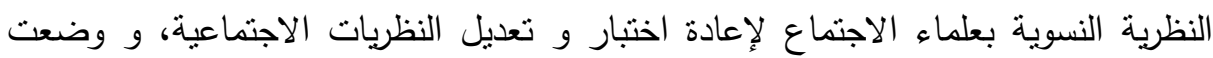

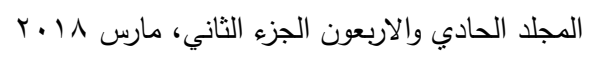


الناشطات أسئلة جذرية عن: (الأدوار الاجتماعية، الهويات حسب النوع و الخصائص

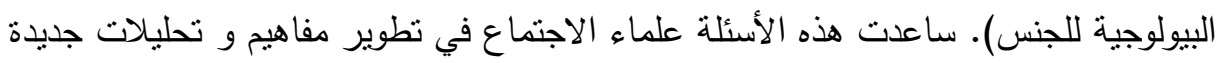

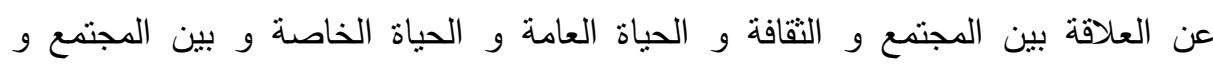
الطبيعة. أما فيما يتعلق بالنماذج النظرية التى تلقى الضوء على وضع المرأة فى سوق العمل،

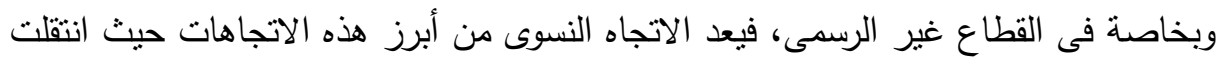

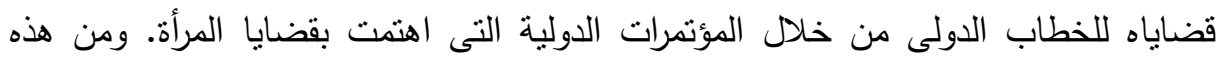

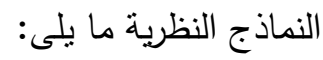
أولاً: النموذج التقليدى: وهو يركز على التقرقة بين الذكر والأنثى فى سوق العمل غير الرسمى، حيث ينظر للمرأة على أنها عنصر وغير فعال اقتصادياً، ومن ثم تفضيل عمالة الذكور على الإناث. كما يشير إلى أهمية دور التنشئة الاجتماعية فى دعم التمييز بين

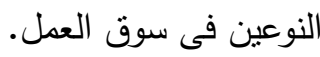
ولقد تعرض هذا النموذج لكثير من الاتثقادات، منها على سبيل المثال أن التمييز

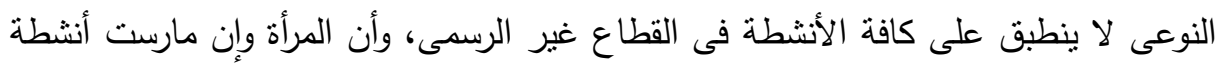

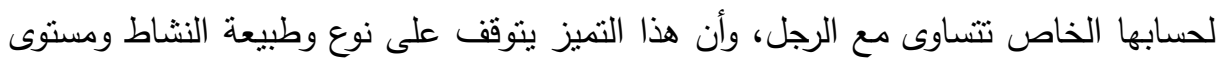
المهارة والأداء والإنجاز الذى يحققه كل منهما (ساصع).

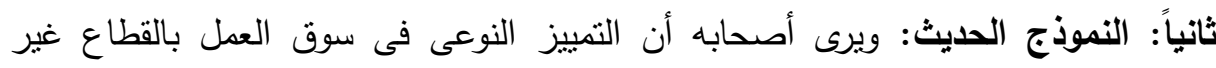

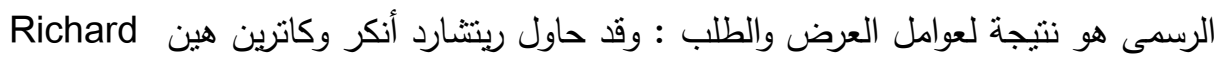
Anker- Catherine Hen عمالة الإناث من خلال بحث أجرته منظمة العمل الدولية فى بعض دول العضى العالم الثالث. وقد أرجعا سبب ذلك إلى عدة أبعاد لها دور هام فى الثييز بين النوعين منها : البعد الثقافى، والبعد القانونى، والبعد التنظيمى( ع ؟). وعلى الرغم من الاختلافات فى الاتجاهات والمداخل النظرية التى تتاولت قضايا المرأة فى سوق العمل الرسمى وغير الرسمى، إلا أن هذا الاختلافات قد نولد نتيجة للحركات الات الندات النسائية

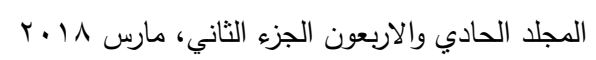


التى ظهرت فى بداية القرن التاسع عشر والتطورات التى لحقت بها حتى القرن العشرين، وخاصة الستينيات منه. ففى أواخر الستينيات ظهرت حركة التحرير النسائى والتى يطلق عليها

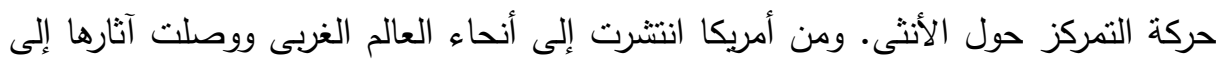
عالمنا العربى. وقد ساعدت هذه الحركة على إيراز بعض قضايا المرأة المعاصرة والتعبير

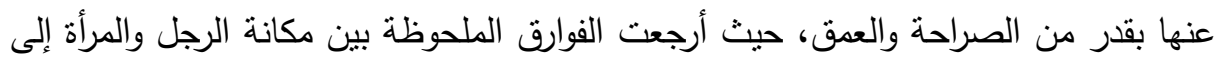

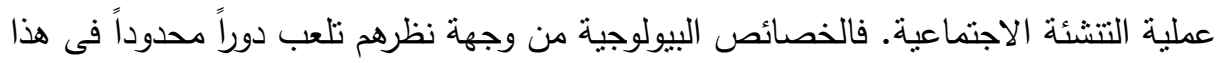
الثأن. ومن ثم فإن مناقثاتهم لقضية المساواة تستتد على اعتقاد بأن الاختلافات البيولوجية

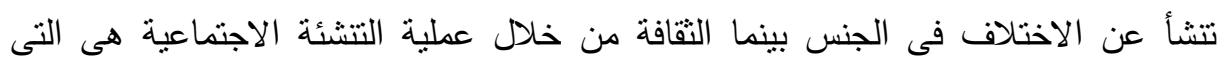

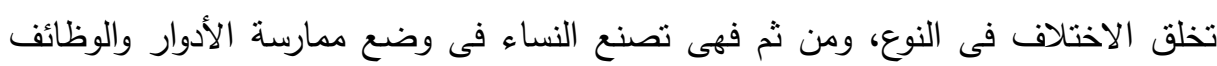

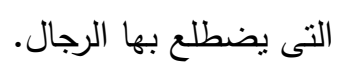

كما نلاحظ أن النظرية النسوية Feminist Theory تتظر إلى المساواة بين الجنسين

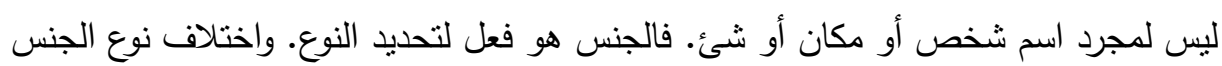

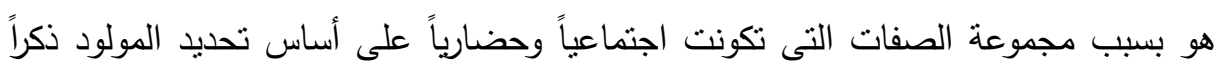
كان أم أنثى. فالبحث فى الوجود من وجهة نظرية المساواة بين الجنسين أو دراسة الوضع إنى

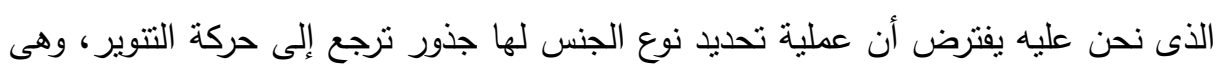
حركة فلسفية أوربية تزامنت فى القرن الثامن عشر الميلادى، وانتظم الفكر فى إطارها إلى نى نى ثنائيات منل : (العقل، الجسد) (العام، والخاص)، (الطبقية، الحضارة)، (الفكر ، العاطفة)( ץ-الجندر: الاهتمام الثاني للإجتماعيات النسويات هو الإدارك والإعتراف بالفروقات البيلوجية الباتية والإجنماعية بين الجنسين. فالقروقات البيلوجية هي تلك الفروقات المرتبطة بالجنس كوصف بيولجي أما الفروقات الإجتماعية فهي تلك الفروقات على التي نرتبط بالبني الإجتماعية كوصف للجندر • وتلاحظ Lovell(2) أن التفريق بين الجنس و الجندر يشكل

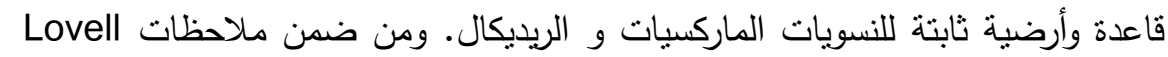
أيضا، أن الوظائف البيلوجية تصيغ بوتيرة متصاعدة عقلانية التبرير و التحليل و التشريع في الذاكرة الإجتماعية لوضع النساء في العالم الإجتماعي. و يمنح جزء كبير من النظرية

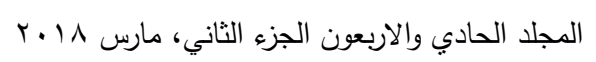


النسوية شروحات وتفسيرات للبنى الإجتماعية التي تحدد هذه الأوضاع و الأدوار وتتنقد

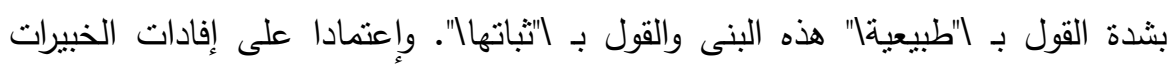
النسويات في هذا المجال، فالملاحظات على أوضاع النساء حسب الزمان ولندان و المكان أنها متباينة ومنتوعة حسب العلاقات الإجتماعية للمرأة و الرجل في تلك المجتعات. تعتقد النسويات أن الخصائص البيولجية قد تكون ثابتة، ولكن العلاقات الإجتماعية المؤسسة في النقافة المجتمعية هي -حرفيا - قابلة لإعادة النتكيل. ورغم ذلك، فليس من السهولة تلكئل

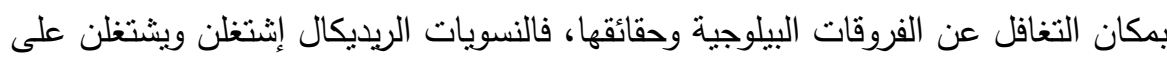

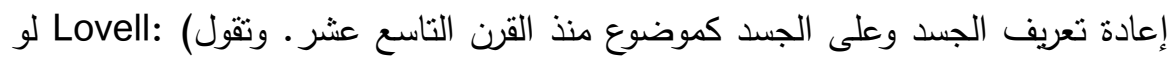
استمر وجود نساء مضطهدات في كل زمان ومكان وبشكل واسع حينها لامجال من تن الإعتراف بأن للفرقات البيلوجية يد في ذلك.

\section{لإيراءاهي السراسما}

تم إجراء هذه الدراسة في محافظة الجيزة. نوع الدراسة: تتنمي هذه الدراسة إلى نمط الدراسات الوصفية المقارنة التحليلية لكونها أنسب أنواع الدراسات ملائمسة لطبيعـة موضوع الدراسـة والتي تهدف إلى وصف وتهـ وتحليل ومقارنة التحديات الاجتماعية والفيزيقية لستخدام المراة للتكنولوجيا الحديثة. منهج الاراسة: وتتنهج الدراسة الحالية منهج المسح الاجتماعي بالعينة بهدف الوصول إلى بيانات يمكن مقارنتها وتصنيفها وتفسير ها وتعميمها وذلك للاستفادة بها في المستقبل وخاصة في الأغراض العلمية؛ ويتمثل المنهج المستخدم في المسح الاجتماعي بالعينة. 
مصطفى إبراهيم عوض وآخرون 


\section{أدوات الدراسة:}

- أداة القياس: اعتمدنا في دراستنا الحاليـة على الاستبيان كأداة من أدوات جمـع البيانات

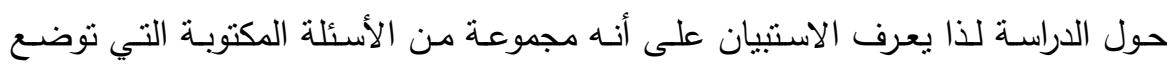
بقصد الحصول على معلومات وآراء المبحوثين حول ظاهرة أو موضوع معين ومن أهم ما الهانه تتميز به الاستبانة هو توفير الكثبر من الوقت والجهد على الباحث، وعلى هذا الأساس تم

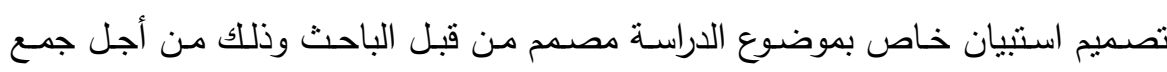

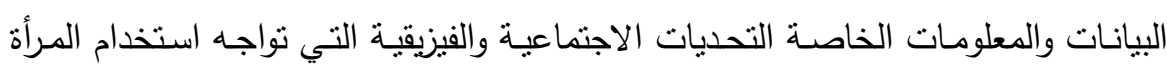
للتكنولوجيا الحديثة. كمـا يتكـون هذا الاستبيان مـن شقين الثـق الأول يتضـمن البنـود الخاصـة بالتحديات

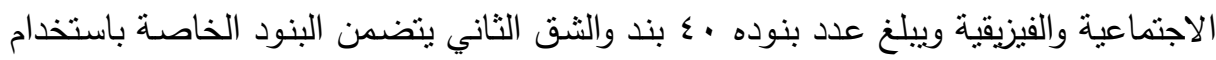
التكنولوجيا الحديثة وييلغ عدد بنوده ـ ب بند.

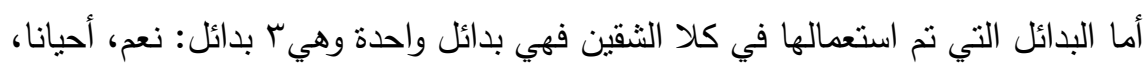

-الخصائص السيكومترية لأداة القياس: للتأكد من أداة الدراسة المستخدمة تستطيع أن تقيس

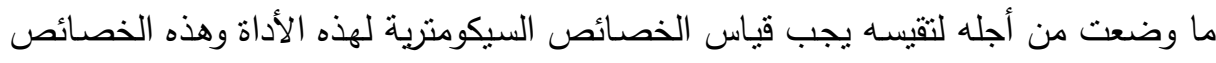
تتمنل في الصدق والثبات وسنتطرق إلى كيفية حساب كل خاصية من هاتين الخاصيتين.

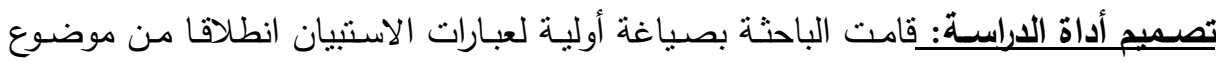

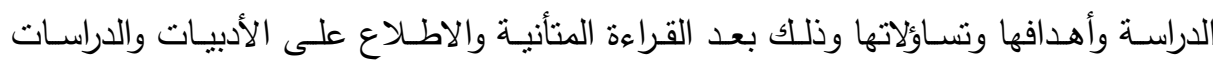

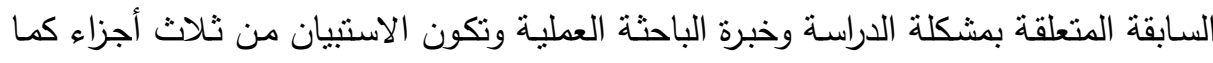

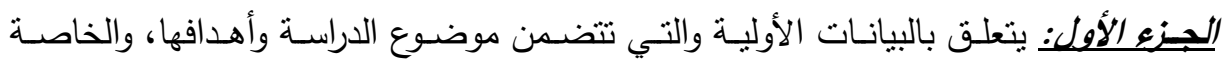

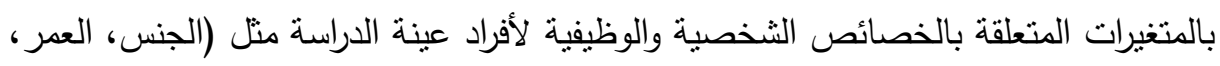


الجزيع الثانسي. يتضمن البنود الخاصة بالتحديات الاجتماعية والفيزيقية ويبلغ عدد بنوده . ؛ بند.

اللجزع الثالث: يتضمن البنود الخاصة باستخدام التكنولوجيا الحديثة ويبلغ عدد بنوده . Y بند. وقد تم قياس استجابات أفراد العينـة لفقرات الاستنيان طبقا لمقياس ليكرت الثلاتثي وقد تم حساب مستوي الأهمية وفقاً للمعادلة التالية: مستوي الأهمية = (الحد الأعلى للإجابة - الحد الأدنى للإجابة) ) الحد الأعلى للإجابة

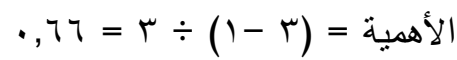
صدق وثبـات أداة الدراسـة:ويشمل وصف أداة الدراسة علي صدق الاتساق الظاهري وثبات وصدق الاتساق الداخلي لأداة الدراسة وذلك على النحو التالي: أولا : صدق الاتسـاق اللـ/خلي: يقصد بصدق الاتساق الداخلي مدى انساق كل عبارة من ودن

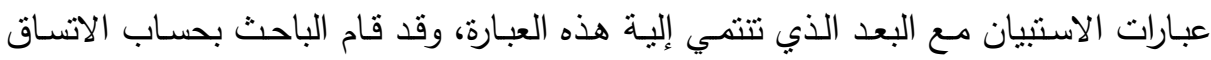

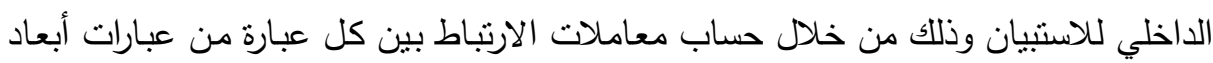
الاستبيان والدرجة الكلية للبعد نفسه. ثانيـا: الصدق البنـائي: يعتبر الصدق البنائي أحد مقاييس صدق الأداة الذي يقيس مدى

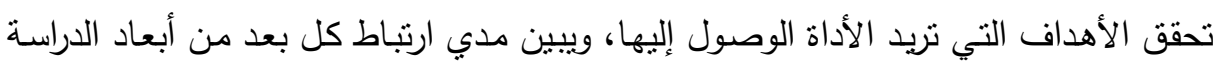
بالدرجة الكلية لعبارات الابعاد. ثالثا: ثبات الاستبيان: يقصد بثبات الاستبيان أن يعطي هذه الاستبيان نفس النتيجة لو تم

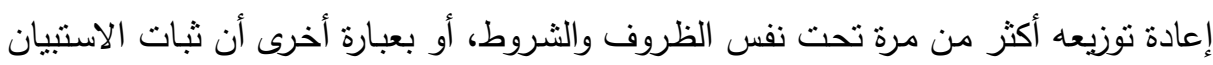

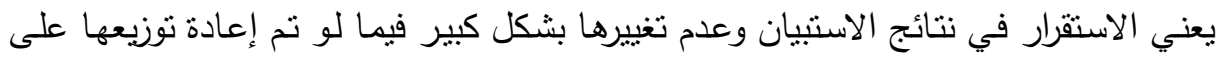
أفراد العينة عدة مرات خلال فترات زمنية معينة. وقد قام الباحث من التحقق من صدق الاتساق الداخلي والصدق البنائي وثبات الاستنيان من من منان خلال تطبيقه على عينة اسنطلاعية مكونة . r سيدة من محافظة الجيزة. 
مجلة العلوم البيئية

معهد الدراسات والبحوث البيئية - جامعة عين شمس لهن 
عينة الاراسة: وقد نألفت عينة الدراسة من:

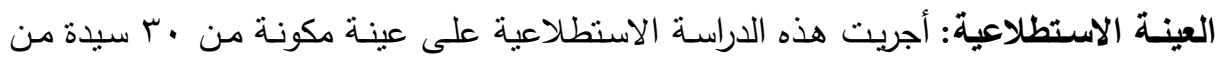

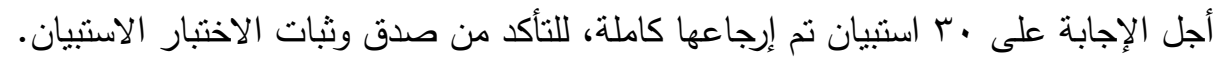
العينة الفعلية: تكونت من . سـ سيدة من محافظة الجيزة. النتائج المتعلقة بوصف أفراد الدراسة (خصائص العينة): وفيما يلي عرض لعينة الدراسة وفق الخصائص الديموغرافية. جدول( ) : توزيع أفراد عينة الدراسة تبعاً لمكان الإقامة لئة

\begin{tabular}{|c|c|c|c|}
\hline النسبة المئوية \% & التكرار & الفئة & المتغير \\
\hline$\overline{~ \% r r ~}$ & 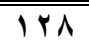 & ريف & \multirow{2}{*}{ مكان الإقامة } \\
\hline$\% \curlyvee \wedge$ & YVY & حضر & \\
\hline$\% 1 \ldots$ & $\varepsilon \ldots$ & & \\
\hline
\end{tabular}

من خـلال استعراض الجدول رقم (1) الخـاص بتوزيع أفراد عينـة الدراسـة تبعـا لمكان

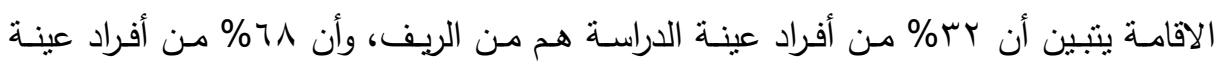

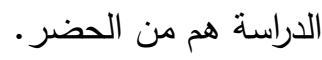
جدول(Y): توزيع أفراد العينة تبعاً للحالة الاجتماعية

\begin{tabular}{|c|c|c|c|c|c|c|}
\hline \multicolumn{2}{|c|}{ الإجمالي } & \multicolumn{2}{|c|}{ حضر } & \multicolumn{2}{|c|}{ ريف } & \multirow{2}{*}{ الحالة الاجتماعية } \\
\hline$\%$ & العدد & $\%$ & العدد & $\%$ & العلد & \\
\hline$\%$ \% , , & $1 \leqslant$. & $\% r \vee, v$ & VY & $\%\{\wedge, \diamond$ & 71 & عزياء \\
\hline$\% \leqslant Y, \wedge$ & $|V|$ & $\% 01,7$ & $1 \Gamma \varepsilon$ & $\%$ \%४,० & $r v$ & متزوجة \\
\hline$\% \backslash \leqslant$, & 07 & $\% \backslash r, r$ & rY & $\% \backslash \vee, r$ & $\bar{r} \leqslant$ & مطلقة \\
\hline$\% \wedge, r$ & $r r$ & $\% \wedge, \xi$ & YY & $\% \vee, \wedge$ & 11 & أرملة \\
\hline$\% 1 \ldots$ & $\varepsilon \ldots$ & $\% 1 \ldots$ & rq. & $\% 1 \ldots$ & $1 \varepsilon$. & الإجمالي \\
\hline \multicolumn{2}{|c|}{ قيمة الدلالة: } & \multicolumn{2}{|c|}{ درجة الحرية df: r } & \multicolumn{2}{|c|}{ аут, ए। } & كا \\
\hline
\end{tabular}

من خـلال استعراض الجدول رقم (Y) الخـاص بتوزيـع أفراد عينـة الدراسـة تبعاُ للحالة

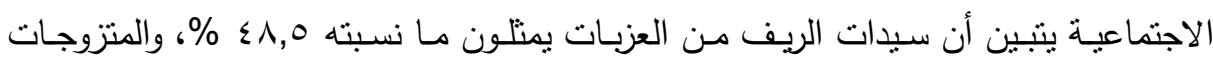

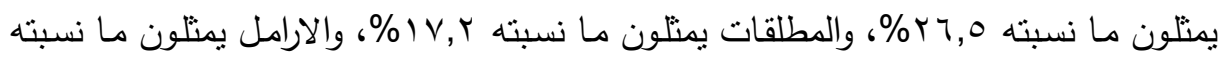
$\% \vee, \wedge$ 
امـا سيدات الحض من العزبـات يمثلون مـا نسبته YV,V \% والمتزوجات يمثلون مـا

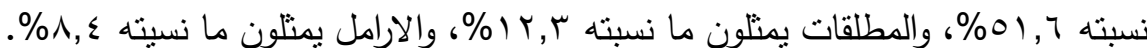

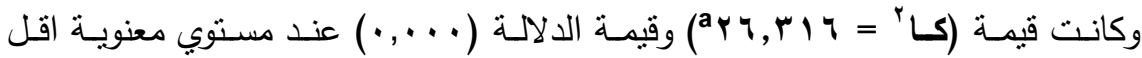
من جدول(ץ): نوزيع أفراد العينة تبعاً للسن

\begin{tabular}{|c|c|c|c|c|c|c|}
\hline \multicolumn{2}{|c|}{ الإجمالي } & \multicolumn{2}{|c|}{ حضر } & \multicolumn{2}{|c|}{ ريف } & \multirow{2}{*}{ الفئة العمرية } \\
\hline$\%$ & العدد & $\%$ & العدد & $\%$ & العدد & \\
\hline$\% 7, \wedge$ & rV & $\% \vee, \wedge$ & rt & $\% \varepsilon, r \varepsilon$ & 0 & اقل من هץ سنة \\
\hline$\% Y_{0,0}$ & $9 \wedge$ & $\% 19,10$ & $0 \leqslant$ & $\% r v, r q$ & $\varepsilon \varepsilon$ & $r \cdot-r r$ \\
\hline$\% r \cdot, r$ & $|r|$ & $\% r \varepsilon, A r$ & $v \cdot$ & $\% \varepsilon r, Y r$ & 01 & ro-r \\
\hline$\% \backslash \wedge$, & VY & $\%$ \%r,Vт & TV & $\% \varepsilon, r \varepsilon$ & 0 & $\varepsilon \cdot-r q$ \\
\hline$\% 11,0$ & $\leqslant 7$ & $\% \backslash r, \cdot 7$ & $r \varepsilon$ & $\% 1 \cdot, 1 \mathrm{~V}$ & Mr & $\varepsilon 0-\varepsilon 1$ \\
\hline$\% q$, & ri & $\% \backslash r, \Sigma \mid$ & ro & $\% \cdot, \wedge 0$ & 1 & أكثر من 0ـ سنة \\
\hline$\% 1 \ldots$ & $\varepsilon \cdots$ & $\% 1 \ldots$ & rAT & $\% 1 \ldots$ & 111 & الإجمالي \\
\hline \multicolumn{2}{|c|}{ قيمة الدلالة: . .,. } & \multicolumn{2}{|c|}{ درجة الحرية df: 0 } & \multicolumn{2}{|c|}{$a_{0}, r, Y V$} & كا' \\
\hline
\end{tabular}

من خلال استعراض الجدول رقم (r) الخاص بتوزيع أفراد عينة الدراسة تبعاُ للسن يتبين

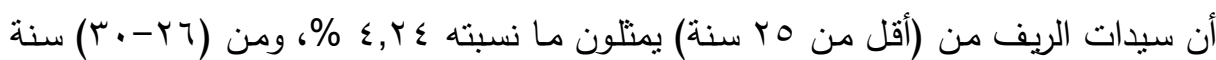

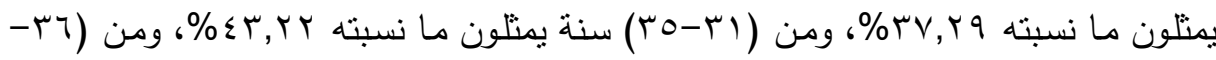

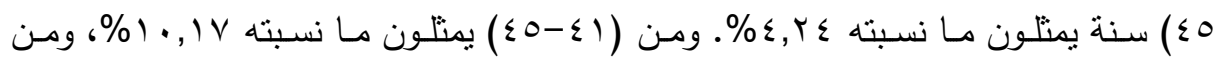

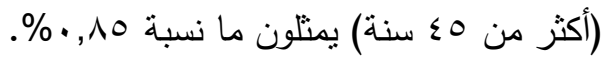

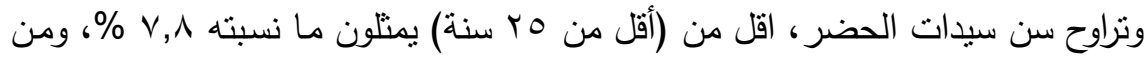

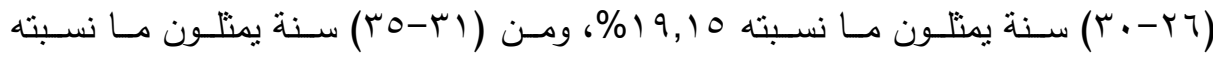

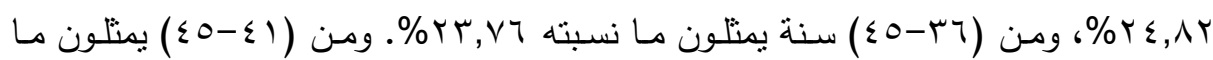

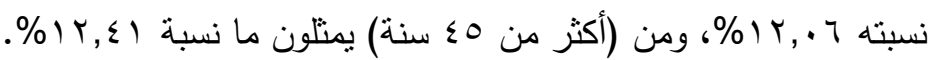




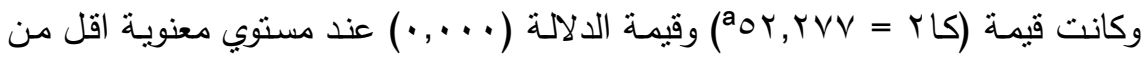

جدول(؛ ): توزيع أفراد العينة تبعاً للمؤهل العلمي

\begin{tabular}{|c|c|c|c|c|c|c|}
\hline \multicolumn{2}{|c|}{ الإجمـالــــ } & \multicolumn{2}{|c|}{ حضر } & \multicolumn{2}{|c|}{ ريـف } & \multirow{2}{*}{ الــــــؤمـي } \\
\hline$\%$ & الـعـد د & $\%$ & الـعـدد & $\%$ & الـعـدد & \\
\hline \% \%, Y० & ro & $\% \varepsilon, 74$ & $\pi$ & $\% q, 9$ \% & IT & لا تقراً وتكتب \\
\hline$\%$ \%, ro & $1 \pi$ & $\% 1, \cdot \wedge$ & $r$ & $\% \wedge, Y_{\top}$ & 1. & تقراً وتكتب \\
\hline$\% \Upsilon, \cdot$ & IT & $\% r, 0 \wedge$ & 1. & $\% 1,70$ & T & ابتدائية \\
\hline$\% r,$. & TY & $\% 1, \vee 9$ & 0 & $\% 0, \vee q$ & $\bar{V}$ & إعدادية \\
\hline$\% 9,0$ & $\Gamma \wedge$ & $\% \varepsilon, 77$ & $\pi$ & $\%$ \%r, , १ & To & ثانوية عامة \\
\hline$\% 7, \vee 0$ & $T V$ & $\% 0, r \wedge$ & 10 & $\% q, q 4$ & TY & دبلوم \\
\hline$\% \leqslant 1,0$ & 177 & $\%\{\vee, r)$ & TKr & $\% \curlyvee \wedge, 1$. & $\Gamma \xi$ & بكالوريوسر \\
\hline$\%$ \% I, vo & $\overline{\Lambda V}$ & $\%$ \%,$\leq \leqslant 0$ & $\overline{v 1}$ & $\% 1 r, Y r$ & 17 & لبسانس \\
\hline$\% r,$. & $\Lambda$ & $\%$ \%, 10 & 7 & $\% 1,70$ & $\bar{T}$ & دبلوح عالى \\
\hline$\% 1,0$ & 7 & $\% 1, \vee \vee$ & 0 & $\% \cdot, \wedge \Gamma$ & $T$ & ماجستير \\
\hline$\% 1,0$. & 7 & $\% r, 10$ & 7 & $\% \cdot, \ldots$ & . & دكتوراه \\
\hline$\% 1 \ldots$ & $\xi \ldots$ & $\% 1 \ldots$ & & $\% 1 \ldots$ & $|r|$ & الإجمالي \\
\hline \multicolumn{2}{|c|}{ قيمة الدلالة: . ., , } & \multicolumn{2}{|c|}{ درجة الحرية df: · ، 1} & \multicolumn{2}{|c|}{$a_{4}\{, 00 Y$} & 5 \\
\hline
\end{tabular}

من خلال استعراض الجدول رقم (§) الخاص بتوزيع أفراد عينة الدراسة تبعاُ للمؤهل

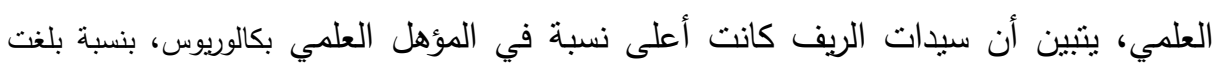

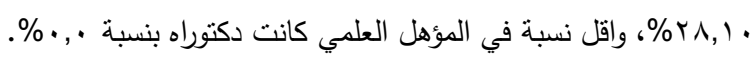

أما سيدات الحضر فكانت أعلي نسبة في المؤهل العلمي لصالح البكالوريوس، بنسبة بلهبة

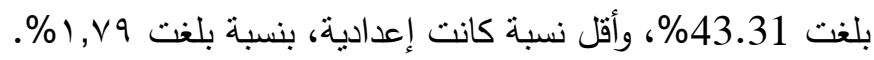

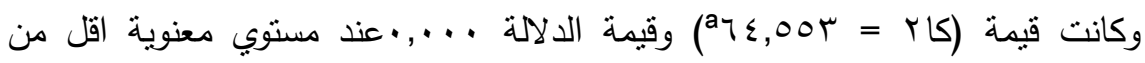

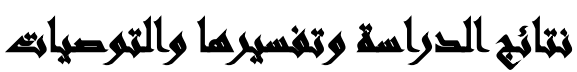

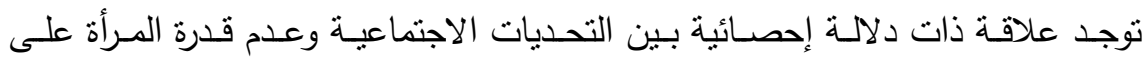

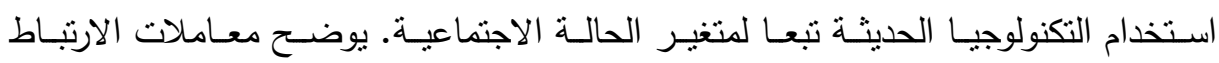


(بيرسون) بين التحديات الاجتماعية وعدم قدرة المرأة على استخدام التكنولوجيا تبعا لمتغير الحالة الاجتماعية.

جدول(0):

\begin{tabular}{|c|c|c|c|c|}
\hline \multicolumn{3}{|c|}{ عدم قدرة المرأة على استخدام التكنولوجيا الحديثة } & \multirow{2}{*}{ الاجتماعية } & \multirow{2}{*}{ المتغيرات } \\
\hline 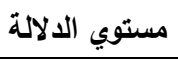 & 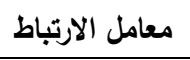 & حجم العينة & & \\
\hline$\cdot, \ldots$ & $(* *) \cdot, \vee \vee \vee 1$ & $1 \leq$. & عزباء & \multirow{4}{*}{ التحديات الاجنماعية } \\
\hline$\cdot, \cdots$ & $(* *) \cdot, \vee \vee \backslash$ & $|v|$ & متزوجة & \\
\hline$\cdot, \cdots$ & $(* *) \cdot, \vee \vee ৭ 4$ & 07 & مطلقة & \\
\hline$\cdot, \ldots$ & $(* *) \cdot, \vee \wedge \vee$ & سץ & أرملة & \\
\hline
\end{tabular}

من الجدول السابق (0) بين التحديات الاجتماعية وعدم قدرة المرأة على استخدام التكنولوجيا تبعا لمتغير الحالة الاجتماعية يتبين الآتي:

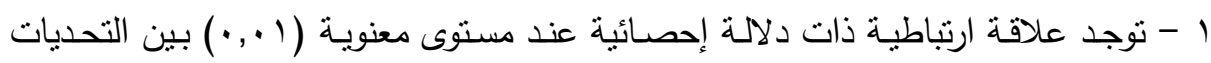

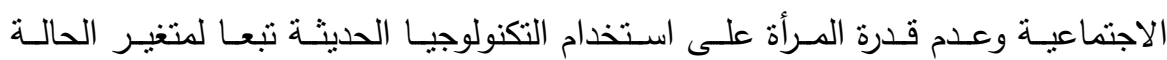

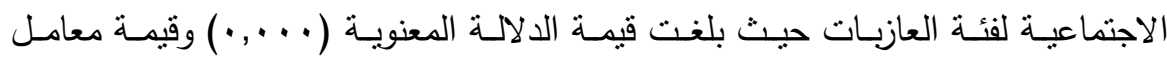

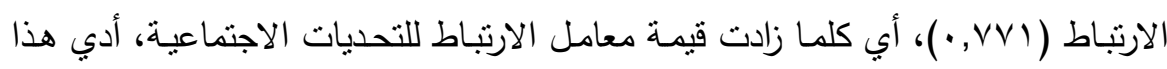
إلي زيادة عدم قدرة فئة العازبات على استخدام التكنولوجيا الحديثة.

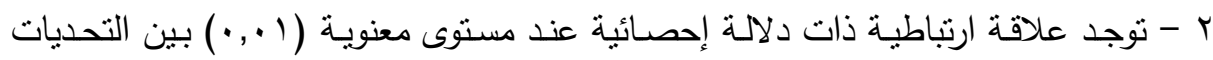

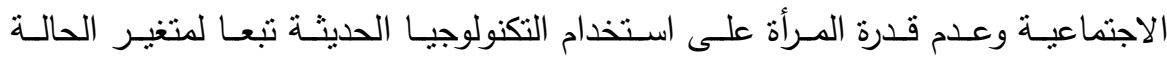

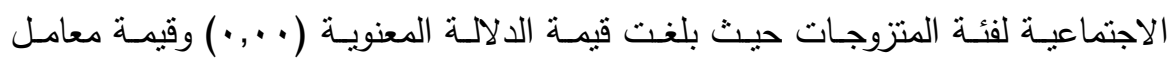

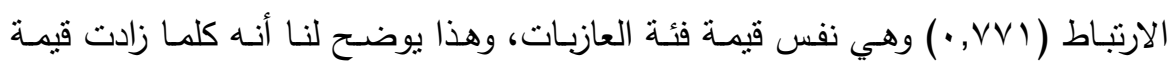

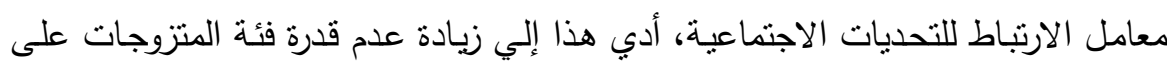
استخدام التكنولوجيا الحديثة. r - توجد علاقة ارتباطية ذات دلالة إحصائية عند مستوى معنوية (1 ., •) بين التحديات

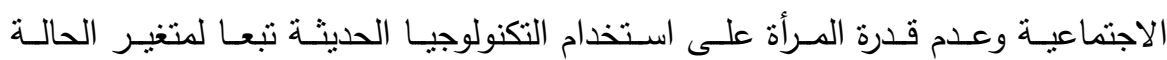
الاجتماعية لفئة المطلقات حيث بلغت قيمة الدلالة المعنوية ( · , •) وقيمة معامل الارتباط 
( V97, •)، أي كلما زادت قيمة معامل الارتباط للتحديات الاجتماعية، أدي هذا إلي زيادة عدم قدرة فئة المطلقات على استخدام التكنولوجيا الحديثة. ع - توجد علاقة ارتباطية ذات دلالة إحصائية عند مستوى معنويـة ( ا.., •) بين التحديات

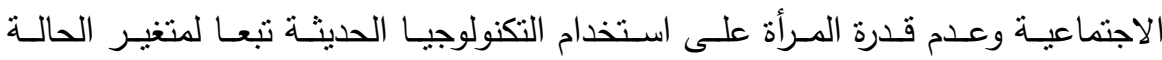
الاجتماعية لفئة الأرامل حيث بلغت قيمة الدالة المعنوية ( · . . ) وقيمة معامل الارتباط

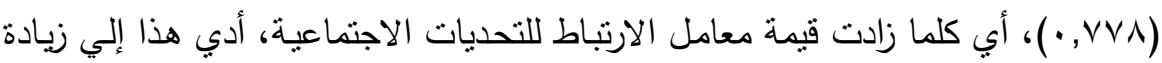

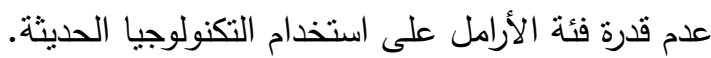

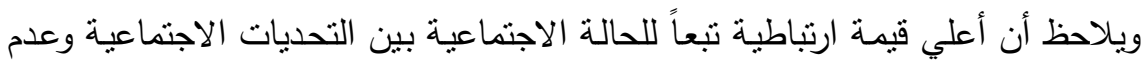

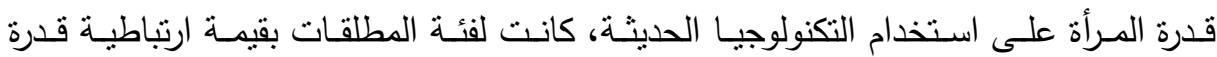

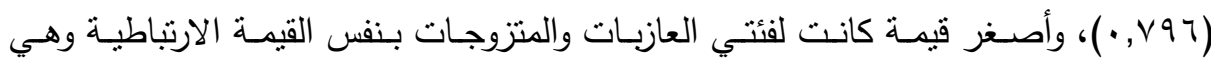

توجد علاقة ذات دلالة إحصائية بين التحديات الفيزيقية وعدم قدرة المرأة على استخدام التكنولوجيا الحديثة تبعا لمتغير الحالة الاجتماعية. 
مجلة العلوم البيئية

معهز الدراسات والبحوث البيئية - جامعة عين شمس لهن

جدول(؟): المتوسطات والانحرافات المعيارية واستجابات عينة الدراسة نحو التحديات الاجنماعية

\begin{tabular}{|c|c|c|c|c|c|c|c|c|}
\hline \multirow{2}{*}{ |المتوسيط |لمئوي | المرجي } & \multirow{2}{*}{ الانحراف المعياري } & \multirow{2}{*}{ |المتوسط } & \multirow{2}{*}{ العدد } & \multicolumn{3}{|c|}{ الاستجابات } & \multirow{2}{*}{ ترتيب الأه } & \multirow{2}{*}{ رقم } \\
\hline & & & & ע & أحيانا & نعم & & \\
\hline VT, Tr & •, Аץ० & $r, r q$ & $\varepsilon \ldots$ & 91 & $\wedge \wedge$ & $r \mid \leq$ & 9 & 1 \\
\hline VT, ד & $\cdot, \wedge т$. & $r, Y_{1}$ & $\varepsilon \ldots$ & $11 \varepsilon$ & AV & 199 & $1 \varepsilon$ & r \\
\hline $97, \cdots$ & $\cdot, \Sigma \backslash V$ & $r, \wedge \wedge$ & $\varepsilon \ldots$ & $1 \leq$ & 19 & rTV & 1 & $r$ \\
\hline 90,77 & $\cdot, \leq 01$ & $r, \wedge V$ & $\varepsilon \ldots$ & 11 & 17 & דוד & r & $\varepsilon$ \\
\hline 10,74 & $\cdot, 771$ & $r, O V$ & $\varepsilon \ldots$ & ऍ^ & 91 & rYะ & $\varepsilon$ & 0 \\
\hline $90, \ldots$ & $\cdot, \leqslant \vee q$ & $r, \wedge 0$ & $\varepsilon \ldots$ & $r \cdot$ & r) & roq & $r$ & 7 \\
\hline | & $\cdot, \mathrm{VOV}$ & $Y, 0 T$ & $\varepsilon \ldots$ & 70 & $\leq 7$ & rAq & 0 & V \\
\hline$\wedge r, T \backslash$ & $\cdot, 79 \vee$ & $r, \Sigma \wedge$ & $\varepsilon \ldots$ & $\varepsilon V$ & 117 & rTV & 7 & $\wedge$ \\
\hline VO, & $\cdot, 9 \cdot r$ & r, T, & $\varepsilon \ldots$ & ITE & $\leqslant V$ & rrq & 11 & 9 \\
\hline$v 0,74$ & $\cdot, \wedge 9 \wedge$ & $r, Y V$ & $\varepsilon \ldots$ & IrT & 0. & TYA & 1. & 1. \\
\hline$V Y, T T$ & •, Nor & $r, 1 \wedge$ & $\varepsilon \ldots$ & 117 & 91 & 1117 & 10 & 11 \\
\hline$\vee 1, \ldots$ & $\cdot, q \cdot r$ & $r, I T$ & $\varepsilon \ldots$ & $1 \varepsilon$. & 79 & 191 & 17 & ir \\
\hline $79, \ldots$ & $\cdot, \wedge 77$ & $r, \cdot V$ & $\varepsilon \ldots$ & דצמו & 99 & 170 & 19 & r \\
\hline$v 0, \ldots$ & •,人৭५ & r, ro & $\varepsilon \ldots$ & IYr & or & YrI & Ir & $1 \varepsilon$ \\
\hline V & $\cdot, 9 \cdot r$ & $r, 11$ & $\varepsilon \ldots$ & $1 \leq \varepsilon$ & $v$. & 1117 & 11 & 10 \\
\hline Tr, Tr, & $\cdot, \wedge \vee \Gamma$ & $r, \cdot r$ & $\varepsilon \ldots$ & $1 \leq \wedge$ & 97 & 107 & r. & 17 \\
\hline VV,r & $\cdot, 101$ & r, rT & $\varepsilon \ldots$ & 1.1 & $v \cdot$ & rrq & $\wedge$ & IV \\
\hline$v \leqslant, \cdots$ & $\cdot, \wedge \wedge$. & T,Y & $\varepsilon \ldots$ & Ir. & vi & $r . q$ & Tr & 11 \\
\hline$V \cdot, T ד$ & $\cdot, \wedge 0 \leq$ & r,IT & $\varepsilon \ldots$ & $1 K \varepsilon$ & $1 . r$ & IVT & IV & 19 \\
\hline V Tr, & צז, • & r,r & $\varepsilon \ldots$ & 94 & $V V$ & r. & V & $r$. \\
\hline$\vee \wedge, \ldots$ & $\cdot, 0 \wedge 7$ & $r, r \varepsilon$ & & & لاجتم & ill & الدر & \\
\hline
\end{tabular}

*تم وضع ارقام الفقرات بترنيب وجودها بقائمة الاستبيان في جميع جداول الدراسة. 
يُظهر الجدول السابق رقم (؟) المتوسطات الحسابية والانحرافات المعيارية لاستجابات

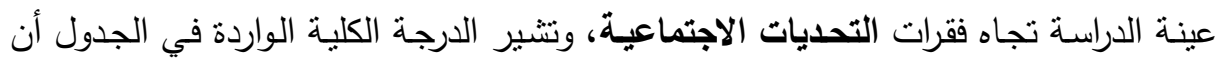
درجة التحديات الاجتماعية لعينة الدراسة متوسطة، حيث بلغ المتوسط الحسابي للارجة الكلية

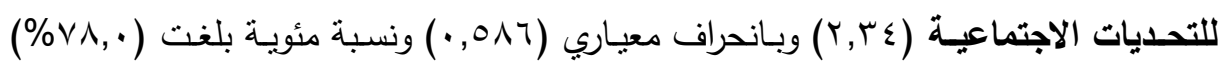
مما يدل على انخفاض التشتت في آراء عينة الدراسة وتقارب الآراء. ويلاحظ في هذا الجدول أن العبارة رقم (ب) قد حصلت على أعلى المتوسطات الحسابية

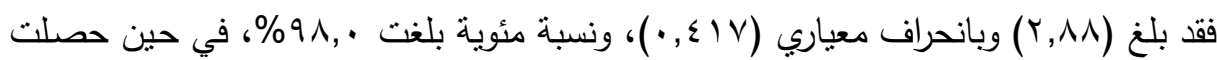

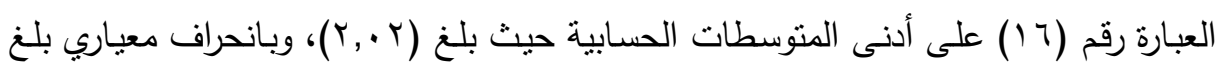

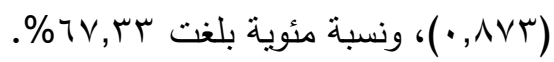


مجلة العلوم البيئية

معهد الدراسات والبحوث البيئية - جامعة عين شمس لهن 
مصطفى إبراهيم عوض وآخرون

جدول(V): المتوسطات والانحرافات المعيارية واستجابات عينة الدراسة نحو التحديات الفيزيقية

\begin{tabular}{|c|c|c|c|c|c|c|c|c|}
\hline \multirow{2}{*}{ 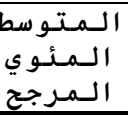 } & \multirow{2}{*}{ الـمـعـــــار افي } & \multirow{2}{*}{ الـــــــوسط } & \multirow{2}{*}{ الـعـدد } & \multicolumn{3}{|c|}{ الاستــــابـــات } & \multirow{2}{*}{ 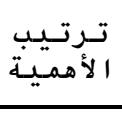 } & \multirow{2}{*}{ الـفـقــــة } \\
\hline & & & & لا & أحيـانــا & نـعم & & \\
\hline$\vee \wedge, \ldots$ & $\cdot, \wedge \bullet 9$ & $r, r \varepsilon$ & $\varepsilon \ldots$ & $1 \cdot r$ & 89 & rrq & $v$ & 1 \\
\hline VY,rr & • & $r, r q$ & $\varepsilon \ldots$ & $9 \wedge$ & $\wedge \wedge$ & ris & 9 & $r$ \\
\hline VT, TY & $\cdot, \wedge ५$. & $r, r_{1}$ & $\varepsilon \ldots$ & $11 \leq$ & $\wedge v$ & 199 & 10 & $r$ \\
\hline ৭४,rr & $\cdot, \leqslant 1 V$ & $r, \wedge q$ & $\varepsilon \ldots$ & $1 \varepsilon$ & 19 & rצv & 1 & $\varepsilon$ \\
\hline 90,74 & $\cdot, \leqslant 01$ & $\curlyvee, \wedge \vee$ & $\varepsilon \ldots$ & 11 & 17 & צו & r & 0 \\
\hline 10,7 & $\cdot, 741$ & Y,OV & $\varepsilon \ldots$ & rq & $9 \wedge$ & YYE & $\varepsilon$ & 1 \\
\hline $90, \ldots$ & $\cdot, \leqslant \vee q$ & $r, \wedge 0$ & $\varepsilon \ldots$ & $r \cdot$ & $r_{1}$ & roq & $r$ & $v$ \\
\hline$\Lambda 0, r r$ & $\cdot, v \odot V$ & Y,0Y & $\varepsilon \ldots$ & 70 & $\leqslant 7$ & $r \wedge q$ & 0 & $\wedge$ \\
\hline Ar,tr &., $79 \vee$ & $r, \leqslant \Lambda$ & $\varepsilon \ldots$ & $\leqslant V$ & 117 & rrv & 7 & 9 \\
\hline vo,rr & $\cdot, q \cdot r$ & Y,Y & $\varepsilon \ldots$ & Irs & $\leqslant V$ & rrq & 11 & 1. \\
\hline V0,7 & $\cdot, \wedge ৭ \wedge$ & $r, r V$ & $\varepsilon \ldots$ & Irr & o. & YrA & 1. & 11 \\
\hline VY,Y & ., nor & $r, 11$ & $\varepsilon \ldots$ & 117 & 91 & 114 & 17 & ir \\
\hline$v_{1}, \ldots$ & $\cdot, q \cdot r$ & r,Ir & $\varepsilon \ldots$ & $1 \leqslant$. & 79 & 191 & iv & ir \\
\hline $99, \ldots$ & •, & $r, \cdot v$ & $\varepsilon \ldots$ & Iry & 99 & 170 & 19 & $1 \varepsilon$ \\
\hline$v_{0}, \ldots$ & •, ^৭ & r, ro & $\varepsilon \ldots$ & Irr & ov & rrI & ir & 10 \\
\hline$v \cdot, r r$ & $\cdot, q \cdot r$ & $r, 11$ & $\varepsilon \ldots$ & $1 \leq \varepsilon$ & $v$. & 114 & 11 & 17 \\
\hline TV,r & $\cdot, \wedge \vee r$ & $r, \cdot r$ & $\varepsilon \ldots$ & $1 \leqslant 1$ & 97 & 107 & $r$. & iv \\
\hline VV,rr & $\cdot, \wedge 01$ & r, rr & $\varepsilon \ldots$ & 1.1 & $v$. & rrq & $\wedge$ & 11 \\
\hline$v \varepsilon, \ldots$ & $\cdot, \wedge \wedge$ & $r, r r$ & $\varepsilon \ldots$ & ir. & vi & $r \cdot q$ & ir & 19 \\
\hline Vr,Y & $\cdot, \wedge 0 \leq$ & $r, I r$ & $\varepsilon \ldots$ & $1 Y \leq$ & $1 \cdot r$ & IVT & $1 \varepsilon$ & $r$. \\
\hline$\vee \wedge, r r$ & $\cdot, O V Y$ & $r, T V$ & & & الفيزيق & J & الدر. & \\
\hline
\end{tabular}

*تم وضع ارقام الفقرات بترتيب وجودها بقائمة الاستبيان في جميع جداول الدراسة.

يُظهر الجدول السابق رقم (V) المتوسطات الحسابية والانحرافات المعيارية لاستجابات عينة الدراسة تجاه فقرات التحديات الفيزيقية، وتثير الدرجة الكلية الواردة في الجدول أن درجة التحديات الفيزيقية لعينة الدراسة مرنفعة، حيث بلغ المتوسط الحسابي للارجة الكلية للتحديات 


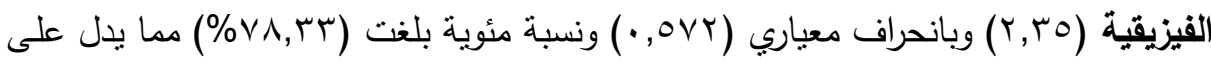
انخفاض النتتت في آراء عينة الدراسة وتقارب الآراء. ويلاحظ في هذا الجدول أن العبارة رقم (ع) قد حصلت على أعلى المنوسطات الحسابية

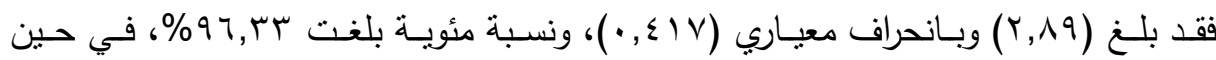

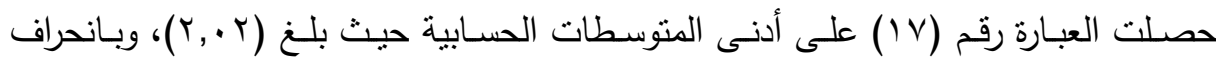

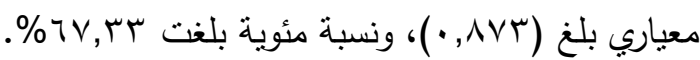

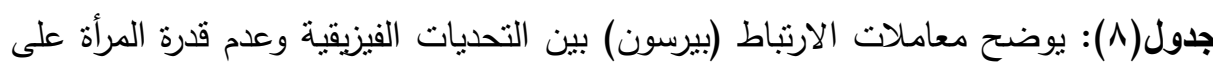
استخدام التكنولوجيا تبعا لمتغير الحالة الاجتماعية.

\begin{tabular}{|c|c|c|c|c|}
\hline \multicolumn{3}{|c|}{ عدم قدرة المرأة على استخدام التكنولوجيا الحديثة } & \multirow{2}{*}{ الاجتماعية } & \multirow{2}{*}{ 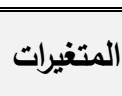 } \\
\hline مستوي الدلالة & معامل الارتباط & حجم العينة & & \\
\hline$\cdot, \ldots$ & $\left(e^{* *}\right) \cdot, \vee \neg \uparrow$ & $1 \leqslant$. & عزباء & \multirow{4}{*}{ التحديات } \\
\hline$\cdot, \ldots$ & $(* *) \cdot, V \vee \cdot$ & $1 V 1$ & متزوجة & \\
\hline$\cdot, \ldots$ & $(* *) \cdot, \vee 99$ & 07 & مطلقة & \\
\hline$\cdot, \ldots$ & $(* *) \cdot, \vee q \varepsilon$ & זי & أرملة & \\
\hline
\end{tabular}

مـن الجـدول السـابق (^) بـين التحـديات الفيزيقيـة وعـدم قدرة المـرأة علـى اسـتخدام التكنولوجيا تبعا لمتغير الحالة الاجتماعية يتبين الآتي:

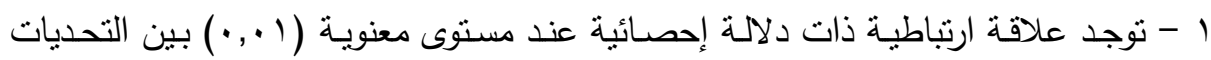
الفيزيقية وعدم قدرة المرأة على استخدام التكنولوجيا الحديثة تبعا لمتغير الحالة الاجتماعية

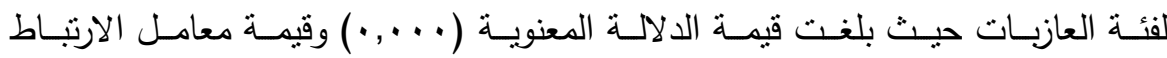

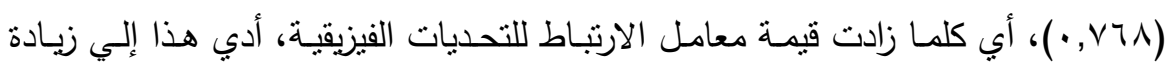
عدم قدرة فئة العازبات على استخدام التكنولوجيا الحديثة. r - توجد علاقـة ارتباطية ذات دلالـة إحصـائية عند مستوى معنويـة ( ( , •) بين التحديات الفيزيقية وعدم قدرة المرأة على استخدام التكنولوجيا الحديثة تبعا لمتغير الحالة الاجتماعية

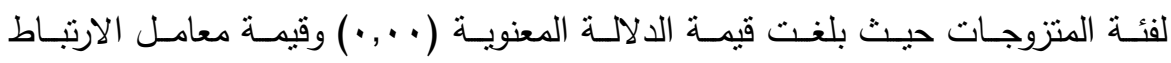

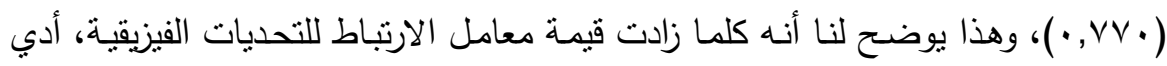
هذا إلي زيادة عدم قدرة فئة المنزوجات على استخدام التكنولوجيا الحديثة. 
r - توجد علاقة ارتباطية ذات دلالة إحصائية عند مستوى معنويـة ( . . •) بين التحديات الفيزيقية وعدم قدرة المرأة على استخدام التكنولوجيا الحديثة تبعا لمتغير الحالة الاجتماعية

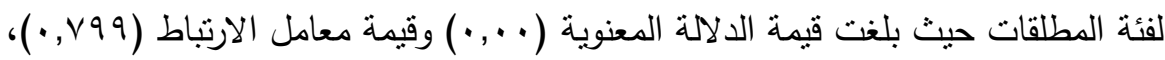
أي كلما زادت قيمة معامل الارتباط للتحديات الفيزيقية، أدي هذا إلي زيادة عدم قدرة فئة ولهة المطلقات على استخدام التكنولوجيا الحديثة.

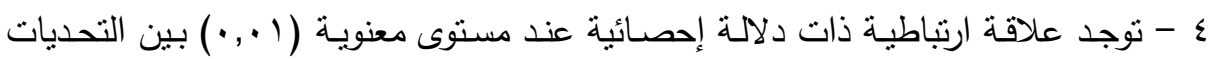
الفيزيقية وعدم قدرة المرأة على استخدام التكنولوجيا الحديثة تبعا لـتغير الحالة الاجتماعية

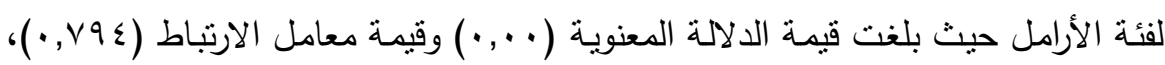
أي كلما زادت قيمة معامل الارتباط للتحديات الفيزيقية، أدي هذا إلي زيادة عدم قدرة فئة الهية الأرامل على استخدام التكنولوجيا الحديثة.

ويلاحظ أن أعلي قيمة ارتباطية تبعاً للحالة الاجتماعية بين التحديات الفيزيقية وعدم قدرة

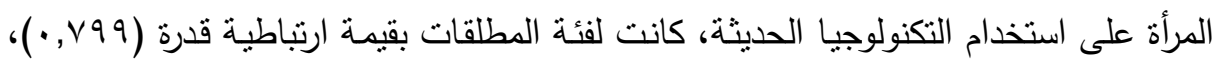

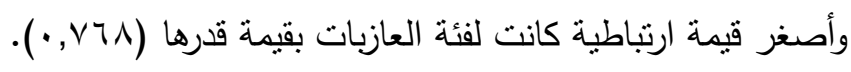

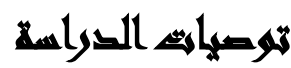

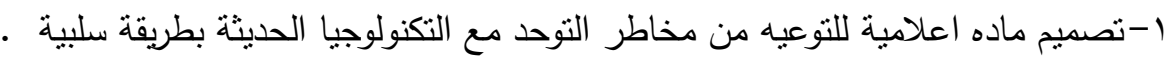
r-توضح الادوار الاجتماعية التى تقوم بها المراء في ظل اتساع الفجواه بين التكنولوجيا

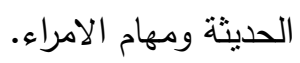

r-اعتماد مجلس المراء برنامج التوعيه الاسرية للحفظ على التمسك الاسري ودور المراء في ذلك .

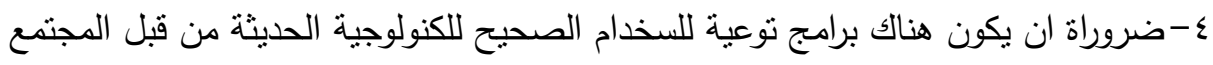

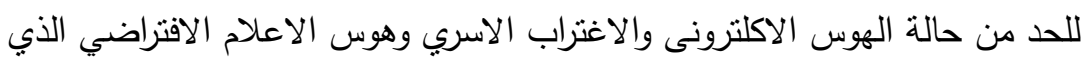

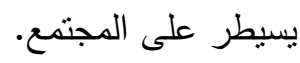




\section{المراليع}

جيهان حداد(r + .rم): المقاهي الالكترونية ودورها في التحول الثقافي في مدينة إربد: دراسة

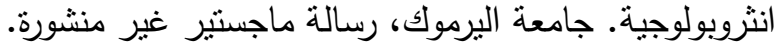

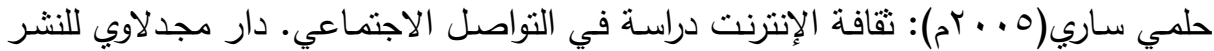

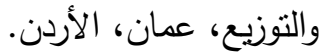

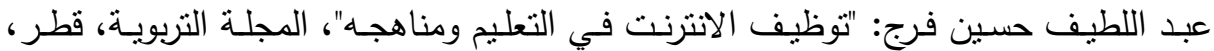

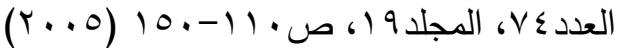

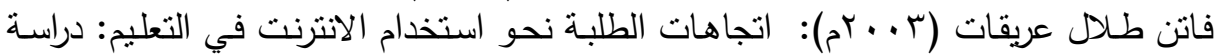
ميدانية على طلبة الدراسات العليا في الجامعة الأردنية، رسالة ماجستير غير التير داتية منشورة.

وائل إسماعيل عبدالباري: "مستقبل تكنولوجيا المعلومات في مصر : دراسة للأبعاد الاجتماعية

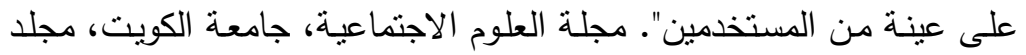

$$
\text { r r }
$$

Sleek, Scott (1998). "Isolation Increases with internet Use". American Psychological Association, vol.29, No.9-September. [web page]. Retrieved July 24,2006, from world wide web:

Kraut, Robert, et al.; (2004). "The Internet and Social Participation Contrasting Cross-Sectional and Longitudinal Analysis". [Web page]. Retrieved July 24, 2006, from world wide web:

Kraut, R., Lundmark, V., Patterson, M., Kiesler, S., Muko., T., and Scherlis, W. (1998). "Internet Paradox: A Social Technology that Reduces Social Involvement and Psychological Well-being". Journal of American Psychologist Sept., vol.53, No.9, p.1017-1031. 
مصطفى إيراهيم عوض وآخرون

\title{
PHYSICAL AND SOCIAL CHALLENGES FACING \\ THE WOMEN'S USE OF MODERN TECHNOLOGY \\ SOCIAL STUDY ON A SAMPLE OF GIZA AREA \\ INHABITANTS
}

Awad, M. I. ${ }^{(1)}$; Hussin, M. A. ${ }^{(2)}$ and Bayoumi, Nancy, H.

1) Institute of Environmental Studies and Research, Ain Shams University

2) Faculty of Arts, Dmietta University

\begin{abstract}
This study is based on the pattern of analytical descriptive studies aimed at describing and analyzing the social and physiological challenges facing women's use of modern technology. This study was conducted in Giza governorate. The theories of the study were from postmodern theory and feminist social theory. The effect of social challenges on the inability of women to use modern technology, as the results of statistical analysis showed a statistically significant impact of the social challenges, and the value of $(\mathrm{k} 2=26.316)$ and the value of significance (0.000) at a significant level less than (0.01) The correlation coefficient was (0.775) at a significant level of 0.05 .

There was a statistically significant correlation between (0.01) between the physical challenges and the inability of women to use the new technology according to the social status of the widows category. The value of significance is $(0.00)$ and correlation coefficient $(0.794)$ This increased the inability of the widows to use modern technology.

The highest correlation between the physical challenges and the inability of women to use modern technology was due to the social situation. The divorced group had a correlation value of (0.799) and the smallest correlation value for single women (0.768).
\end{abstract}

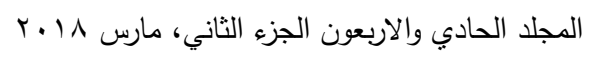


مجلة العلوم البيئية

معهد الدراسات والبحوث البيئية - جامعة عين شمس

Recommendations of the study: To raise awareness of the correct use of modern technology and explain the social roles played by the mirrors in light of the widening gap between modern technology and the tasks of princes. 